\title{
A Survey on Battery-Less RFID-Based Wireless Sensors
}

\author{
Nabil Khalid ${ }^{1}$ (D), Rashid Mirzavand ${ }^{1}$ (D) and Ashwin K. Iyer 2,*(D) \\ 1 Intelligent Wireless Technology Lab., University of Alberta, Edmonton, AB T6G 2R3, Canada; \\ nkhalid1@ualberta.ca (N.K.); mirzavan@ualberta.ca (R.M.) \\ 2 Department of Electrical and Computer Engineering, University of Alberta, Edmonton, AB T6G 2W3, Canada \\ * Correspondence: iyer@ece.ualberta.ca
}

Citation: Khalid, N.; Mirzavand, R.; Iyer, A.K. A Survey on Battery-Less RFID-Based Wireless Sensors.

Micromachines 2021, 12, 819.

https://doi.org/10.3390/mi12070819

Academic Editors: Faisal Mohd-Yasin, Khaw Mei Kum and Teh Ying Khai

Received: 30 May 2021

Accepted: 9 July 2021

Published: 13 July 2021

Publisher's Note: MDPI stays neutral with regard to jurisdictional claims in published maps and institutional affiliations.

Copyright: (c) 2021 by the authors. Licensee MDPI, Basel, Switzerland. This article is an open access article distributed under the terms and conditions of the Creative Commons Attribution (CC BY) license (https:// creativecommons.org/licenses/by/ $4.0 /)$.

\begin{abstract}
We present a survey on battery-less Radio Frequency Identification (RFID-based wireless sensors that have emerged in the past several years. We discuss the evolution of RFID turning into wireless sensors. Moreover, we talk about different components of these battery-less RFID-based wireless sensors, five main topologies that transform a simple RFID chip into a battery-less wireless sensor, and state-of-the-art implementations of these topologies. In battery-less wireless sensors, the read range is of key importance. Hence, we discuss how each component of the sensor plays its role in determining the read range and how each topology exploits these components to optimize read range, complexity, and/or cost. Additionally, we discuss potential future directions that can help provide improvements in RFID-based wireless sensor technology.
\end{abstract}

Keywords: battery-less; IoT; radio frequency identification (RFID); sensor; zero-power

\section{Introduction}

Wireless sensors are becoming increasingly popular in the home and industrial sectors and are used for a range of applications, from temperature or humidity monitoring to foodquality inspection of products being sold on the market. One of the main reasons for using wireless technology is that it affords non-contact, noninvasive sensing. This ability not only eliminates the need for long cables required for information transfer but also reduces the spread of germs and brings comfort to the users. To fully exploit the capabilities of wireless sensors and automatic processes, the future generation of wireless communication, 5G, and the evolving Industry 4.0 aims to incorporate them on a massive scale, due to which research on wireless sensors is on a dramatic rise [1-3].

For the past two decades, Radio Frequency Identification (RFID) has been widely used for object identification and tracking purposes [4]. It took many years for this technology to become affordable and reliable in a variety of applications. The technology was initially focused on replacing bar codes and Electronic Article Surveillance (EAS) to prevent theft. Later on, the application horizon of RFID became wider, and it was introduced in several applications such as tracking inventory at a warehouse for supply management purposes, automated toll collection without the need for stopping, and automatic unlocking of doors when entering parking structures or buildings premises [5,6].

As time passes, the applications of RFID are rapidly expanding, and RFID-based sensors are one of its most interesting applications. Initially, RFID technology was merely introduced for object identification. By the year 2004, the technology started incorporating sensing capabilities [7]. Although extending the chip's capability from identification to sensing is straightforward, the design must ensure that the extension does not affect the performance of an RFID tag. Hence, such an addition should collect sufficient power to run the RFID chip and the sensing element without having any significant impact on the read range of the RFID tag [8,9].

RFID tags are generally classified into three categories: active, semi-passive, and passive, as shown in Figure 1. An active RFID tag has its own power supply and a transmitter 
for communication, whereas a semi-passive RFID has its own power source but does not have any transmitter and, instead, uses a backscattering technique for establishing communication. On the other hand, a passive RFID chip, which is often the cheapest variety, has no internal power source and no transmitter and, thus, uses the power of the electromagnetic field transmitted by the reader to power-up its circuitry and to backscatter the received signal [10-12].

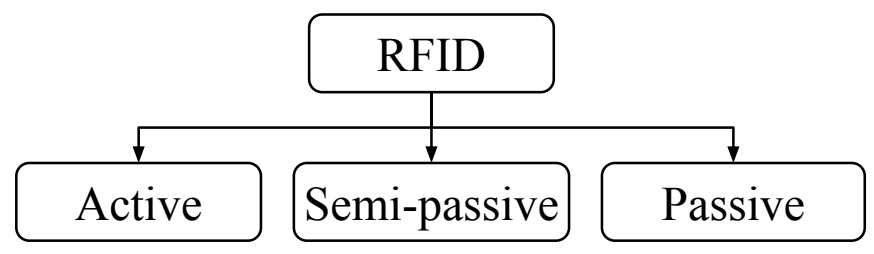

Figure 1. Taxonomy of RFID tags available on the market.

A sensing element may be incorporated in any of the aforementioned categories to design an RFID sensor. Using active or semi-passive technology requires a power source, which makes the wireless sensor bulky and expensive, whereas passive technology is much cheaper, but incorporating sensing elements in it is quite challenging due to the limited available power and flexibility. Hence, passive technology must be carefully engineered to address these challenges [3,11,13-20].

RFID is now a widely used technology for tracking and inventory management services and, as such, is governed by several design standards [21]. However, wireless sensors, especially RFID-based sensors, are still an emerging technology and, therefore, might be referenced using different names in the community. Particularly, passive wireless sensors are sometimes also termed battery-less, self-powered, or even zero-power [8,11,12,22-28].

Battery-less RFID-based wireless sensors have gained a lot of interest because they are lightweight, cheap, and long-lasting. In particular, the ones operating at ultra-high frequency (UHF) are of greater interest as they offer a good compromise between size and read range. An illustration showing the operation of battery-less wireless sensors is shown in Figure 2. There are several different designs proposed in the past that can be generally categorized into chip-less sensors, chip-based antenna resonance modifying sensors, multi-port chip-based sensors, digitally integrated sensors, and chip-based ambient energy-harvesting sensors. In the following sections, we discuss these categories in detail and observe the benefits and drawbacks of each [8,29-49].

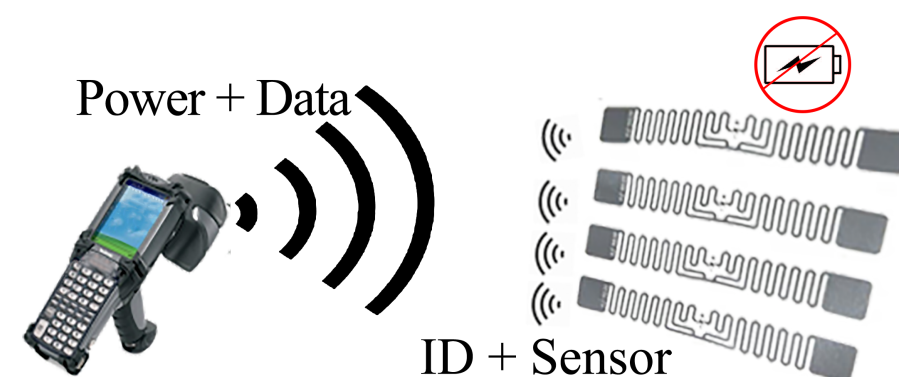

Figure 2. Battery-less wireless sensors draw energy from the reader and respond by backscattering the incident power signal.

The remainder of this paper is organized as follows. In Section 2, we discuss the individual components of RFID-based wireless sensors to develop a basic understanding of how they may be engineered to meet the requirements, e.g., complexity, cost, size, read range, and accuracy of a given application. In Section 3, the system topologies of different categories of battery-less RFID-based wireless sensors are discussed in the context of their complexity, cost, size, read range, and accuracy. Section 4 shows some examples of the implemented circuits that were selected based on their simplicity in design, completeness 
of the description in the article, price affordability, compactness in size, and adequate read range. The section also presents techniques to test each topology. Finally, potential future directions are presented in Section 5, and then, the paper is concluded in Section 6.

\section{Individual Components of an RFID-Based Wireless Sensor System}

An RFID-based wireless sensor consists of several components. A block diagram of all the key components is shown in Figure 3, and details of each component are discussed below.

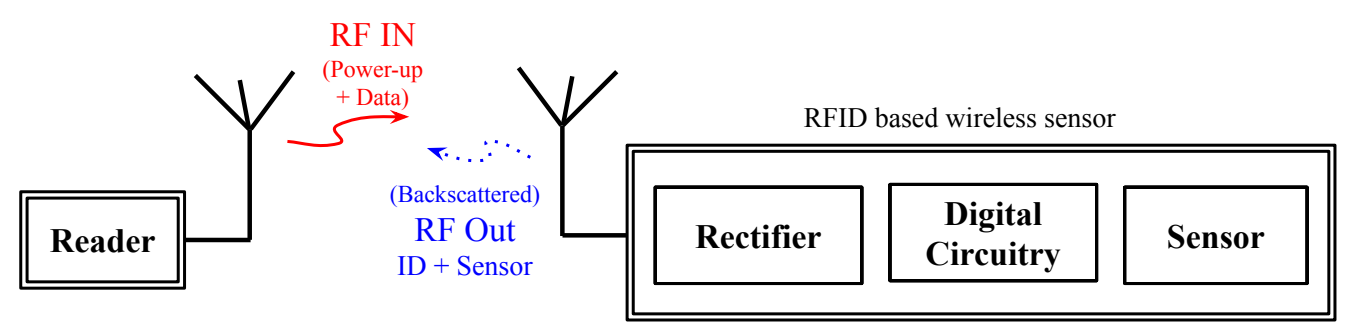

Figure 3. Components of an RFID-based wireless sensor system.

\subsection{Antenna}

An antenna is a transducer that converts free space electromagnetic energy to guided electromagnetic energy and vice versa to enable wireless communication in an RFID system. Although any radiating structure can be termed as an antenna, the efficiency with which it can transform the electromagnetic energy plays a major role in determining its amenability for use in sensor communication [29].

To design antennas, certain characteristics are of key importance. These characteristics are the resonant frequency, bandwidth, impedance, gain, radiation pattern, and polarization. Any design is a trade-off of these characteristics and must be optimized based on the application of interest. In an RFID-based sensor, usually small size, planar, and high gain antennas are desired to ensure longer read range and lower fabrication cost [50,51].

To achieve a small size, different miniaturization techniques are used. Amongst them, meander line antennas are of great interest due to their simplistic design [52-59]. In these antennas, the antenna arms are folded to reduce the size and to produce distributed capacitive and inductive reactance that produces a global effect on the antenna impedance. Operating an antenna well below its natural resonance frequency to satisfy space constraints implies that the antenna becomes more difficult to match, and impedance matching directly impacts the RFID read range. Therefore, the reactance must be properly engineered to effectively reduce the size of the antenna $[60,61]$.

Although a significantly smaller size can be achieved with meander line dipole antennas, they are prone to degradation due to nearby objects and cannot be placed directly on metallic surfaces. Therefore, for applications where a wireless sensor is required to be placed on a metallic object, different classes of antennas may be considered. Normally patch antennas have a ground plane attached on one side and can thus be used for this purpose. However, due to their large size at UHF frequencies, modified versions such as fractal and meandered patch antennas are preferred for RFID tags [51,62-65].

\subsection{Rectifier}

A rectifier in an RFID tag is the main circuit that converts the incident electromagnetic energy received by the antenna into a DC supply voltage. This voltage is required to operate all the internal circuitry of the tag, which includes the analog circuitry, base-band DSP circuitry, and memory of the tag [66-70].

The power efficiency and stability of the rectifier are determining factors for the range of the RFID tag. Generally, Schottky diodes are used in AC/DC rectifiers; however, for RFID tags, they are avoided. This is because they cannot be co-fabricated with CMOS technology, which is required for DSP and memory design. In contrast, separate fabrication of both would result in inconsistencies that degrades the performance of the chip. Therefore, 
diode-connected MOS FETs are preferred when designing RFID rectifiers as they can be accurately co-fabricated with other components $[66,71]$. A detailed model incorporating the fabrication process yields rectifiers with optimal performance [72-75].

If standard threshold voltage CMOS devices are used, the rectifier cannot be turned on when the voltages at its terminals are lower than its turn-on voltage, which affects the read range of the RFID tag. Solutions using near differential-drive rectifier, photovoltaic-assisted rectifier, and zero threshold-based technologies such as Silicon-on-Sapphire and Heterojunction Tunnel FET provide a significant improvement to the read range [44,76-84].

\subsection{Digital Circuitry}

Generally, an RFID tag consists of digital circuitry that is used to transmit the identity data of the chip. This circuitry obtains data from the memory of the tag and modulates it over the backscattered signal. To integrate a sensing element into an RFID tag, an additional digital circuitry that can utilize off-the-shelf sensing elements may be added. This addition allows for recording of sensed data directly inside the tag and for sending it back to the reader using digital modulation techniques along with the identification data. The major benefit of this technique is that the accuracy of the sensor can be very high [23]. However, a clear drawback is that this digital circuity requires additional power. For passive RFID tags, power is limited, and these additional circuits can only operate at the expense of a read-range reduction.

On-chip digitally integrated sensors consist of three major blocks: a digital control circuit, an off-the-shelf sensing element, and an analog-to-digital converter (ADC). The digital control circuitry drives the sensing element by providing the required current or voltages. The element generates an analog voltage based on the physical parameter being measured. This voltage is converted into a digital format using the ADC and transmitted back to the reader using the aforementioned RFID circuitry. Using this technique, different sensors such as temperature, gas, and food-quality sensors can be easily connected $[23,34,85,86]$.

\subsection{Sensing Element}

The sensing element is the heart of the wireless sensor. It is the component that is actually sensitive to the parameter of interest. From this point of view, there are two types of sensing elements: resistive and reactive [87-90]. Resistive sensing elements are the ones for which the resistance across the terminals changes with variations in the physical parameter being measured. Similarly, reactive sensing elements are usually capacitive or inductive in nature and their reactance varies. Resistive sensing elements are usually lossy as power must be dissipated to read their value. On the other hand, reactive sensing elements, especially the capacitive variety, can be very energy-efficient as very little current is drawn to operate them. A simple structure of resistive and capacitive type humidity sensors is shown in Figure 4 [91].

Based on the layout or packaging design, sensing elements can exhibit certain parasitics. As a result, not all sensing elements can be used at high frequencies, such as those employed in RFID. If an on-tag digital circuitry for the tag exists, generally off-the-shelf sensing elements may be used. However, if the topology being used drives the sensing element using a high-frequency incident signal, then the sensing element must be responsive and sensitive at the frequency being used. In this case, a reader must be able to understand the received information and to separate it from the regular RFID's identity information. Elements operating at high frequencies are not easily obtainable on the market. As a result, different types of sensing elements for RFID sensors are currently being explored by researchers to increase their frequency of operation while simultaneously reducing their power consumption [34,35,92-98]. 


\section{Electronic Humidity Sensor}

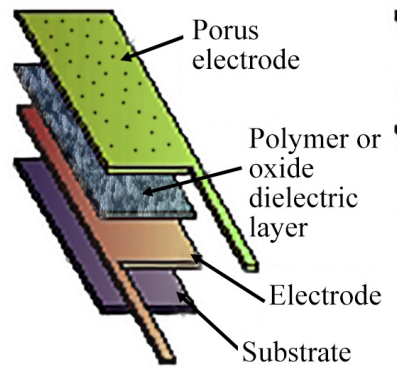

Capacitive

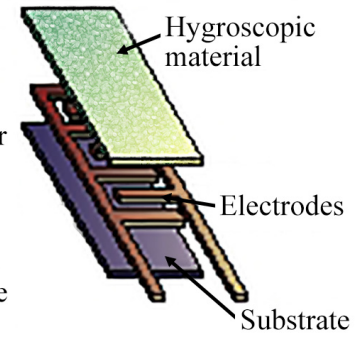

Resistive

Figure 4. Design comparison of resistive- and capacitive-type humidity sensors.

\section{System Topologies}

Different arrangements and utilization of the RFID tag's components can result in different topologies. There are five principal topologies used, each offering different levels of complexity, cost, read range, and accuracy. Here, the details of each topology are discussed to analyze their pros and cons.

\subsection{Chip-Less RFID Sensor Topology}

The simplest form of RFID sensor requires no integrated circuits (ICs) and communicates sensed data by simply varying the radar cross section (RCS) of the tag at a certain frequency [8,29-32]. This is achieved by attaching a sensor, having an input impedance of $Z_{S}$, with an antenna, having an input impedance of $Z_{A}$, through a matching network. A block diagram is shown along with an example of a strain sensor in Figures 5 and 6, respectively. RCS is a combination of structural-mode reflection and antenna-mode scattering. An incoming electromagnetic wave is partly absorbed and partly reflected from the surface of the antenna. The signal reflected from the surface is known as a structural-mode reflection, whereas any part of the absorbed signal that is reflected due to impedance mismatches is known as antenna-mode scattering [99-102]. The sensing element, which could be designed for sensing temperature, humidity, or gas, transforms any change in the physical quantity into a variation in its electrical properties such as resistance or reactance. As a result, the resonance frequency or the quality of the matching network is altered. Hence, this causes a change in the RCS of the antenna at a given frequency.

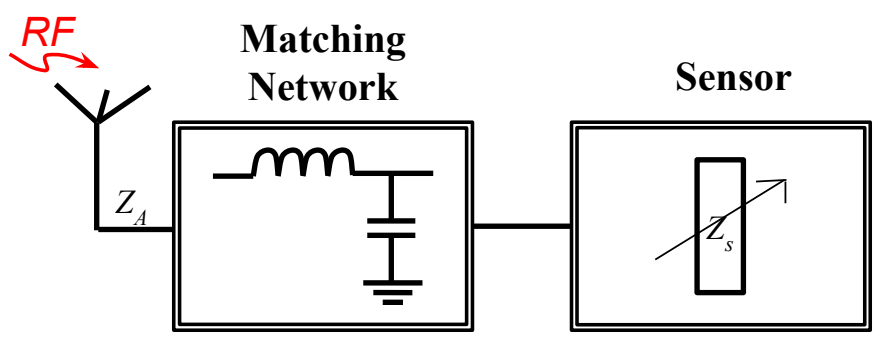

Figure 5. Block diagram of a chip-less RFID-based wireless sensor.

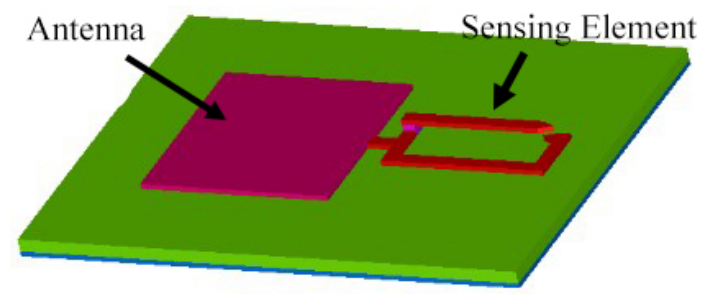

Figure 6. A chip-less RFID-based wireless strain sensor design [30]. 
To read data from a chip-less RFID sensor, a reader transmits a frequency sweep signal of a specific bandwidth and analyzes the backscattered signals that it receives. These backscattered signals are affected by the physical location of the sensor and its RCS. If the physical location and distance between the sensor and the reader are fixed, then the effect of the physical location can be easily factored out to determine the RCS, specifically of the sensor.

When the antenna impedance $Z_{A}$ is matched to the sensing element's impedance $Z_{S}$, the reflection goes to zero and the RCS drops to a minimum. As the mismatch increases with a change in the impedance of the sensing element, which is affected by the physical condition being sensed, the mismatch between the antenna and the sensing element increases. This eventually increases the RCS of the sensor. As a result, the amplitude of the backscattered signal increases. This increase is directly related to the sensing element and can be easily translated to the change in the physical quantity by using predetermined calibration coefficients.

Another perspective to understand this type of sensor is that, when the sensing element mismatches, the resonance frequency of the circuit shifts and, thus, the sensor is matched to another neighboring frequency. The reader can easily search this resonance by measuring the backscattered signal at different frequencies and by matching it with the predetermined calibration data to determine the sensor value and the corresponding physical quantity [103-106].

Although the aforementioned is by far the most cost-effective method of RFID sensing, it requires a higher frequency bandwidth and is also prone to multi-path and environmental effects. Moreover, areas having multiple sensors in close proximity are not supported. Therefore, this method is mostly preferred in uncluttered areas such as farms or fields. There are techniques where multiple resonators are used so that data in multiple frequency bands could be analyzed to reduce the effect of multi-path and environmental noise [95]. Moreover, diode frequency doubling is sometimes used in the sensor so that reception at the higher harmonic is free of environmental backscatter, which is high at the actual frequency of transmission [107-109]. Another technique is to use a direct conversion six-port network in which information is divided into in-phase and quadrature components. The reference signal for calibration purposes is sent as an in-phase component while the sensing element signal is sent as the quadrature component so that they could be analyzed together to determine the sensed value $[110,111]$. Nevertheless, these techniques increase the cost and reduce the read range of chip-less wireless sensors. The read range demonstrated by these sensors ranges from $2 \mathrm{~m}$ to $30 \mathrm{~m}[8,29,95,103-106,110,111]$. Moreover, due to multi-path and analog communication, the accuracy of these sensors is low.

\subsection{Chip-Based RFID Sensor Topology}

To address the challenge of multi-path propagation and to support multiple sensors in close proximity, wireless sensors must incorporate digital communication techniques. This is achieved in chip-based RFID tags, where the backscattering is digitally controlled and acts as a digitally modulated signal. This enables assigning a unique identifier to multiple tags in a vicinity, employing anti-collision protocols, and providing error reduction methods. All of these techniques are built into the RFID EPC-Gen2 protocol. Chip-based RFID tags based on this protocol can be modified in several ways to integrate sensors inside them. These modifications generally include an antenna-resonance shifting-based sensor, a multi-port architecture to remove the sensing element from the incoming signal path, a digitally integrated sensor using digital circuitry, and an ambient energy-harvesting block to get additional power from the surroundings.

\subsubsection{Chip-Based Antenna Resonance Topology}

One of the simplest topologies of chip-based RFID sensors operates on principles that are very similar to chip-less RFID sensors. Generally, the RFID tag is connected to an antenna using some kind of matching network. The matching network has a resonance at 
a particular frequency. Any change in the reactive or resistive component of the matching network shifts its resonance frequency or alters the loss of the network. As a result, the RCS of the RFID tag varies [33-38].

To read data from wireless sensors working on the chip-based antenna resonance topology, a reader first sends an interrogation signal. This signal energizes the rectifier circuitry, and when the charging reaches a threshold level, the IC wakes up. The IC backscatters the interrogation signal by shorting and matching its terminal to send binary signals. As a result, the backscattered signal amplitude increases or decreases and the reader determines the high and the low signal. This information is used to demodulate the data being sent by the RFID tag. Since the sensing element influences the matching network of the RFID tag, the backscattered signal is different at different frequencies. The reader can simply sweep the frequency of its interrogation signal to determine the tag's RCS at different frequencies. By utilizing the digital signal and the amplitude of the backscattered signal at different frequencies, the reader identifies the tag and determines the sensed value, respectively. A block diagram of this topology is shown in Figure 7, and an example of such a sensor is shown in Figure 8.

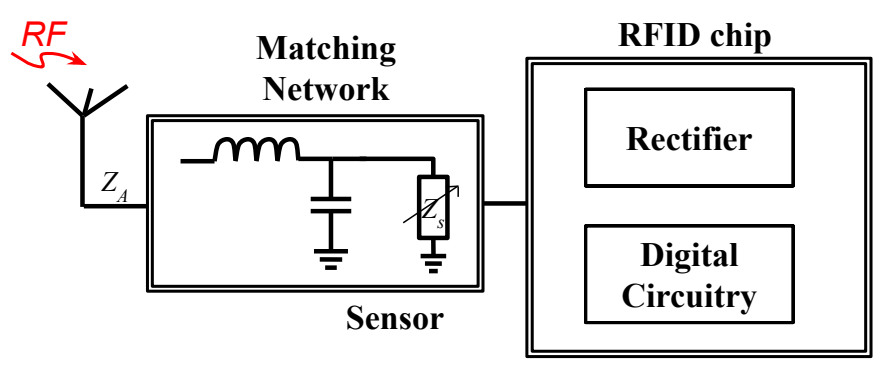

Figure 7. Block diagram of a chip-based antenna resonance wireless sensor.

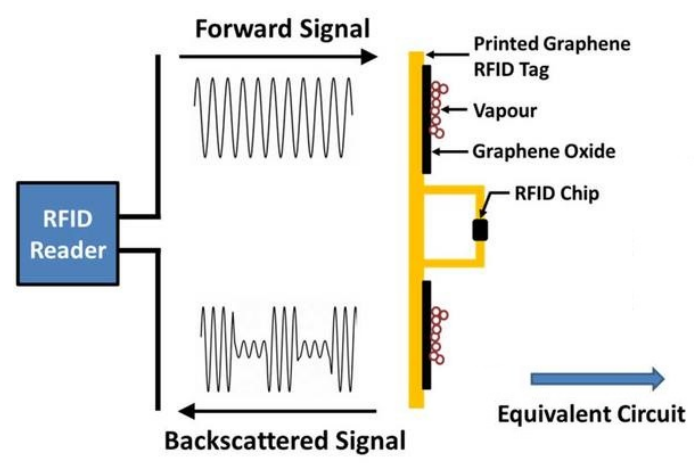

(a)
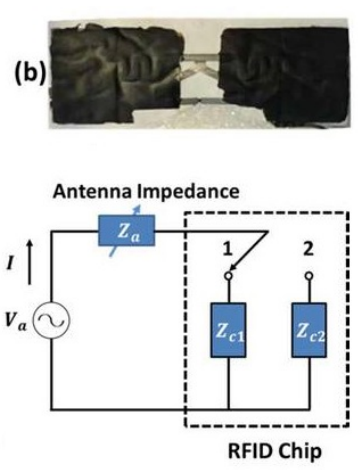

(c)

Figure 8. (a) Operating principle of the chip-based antenna resonance RFID sensor. (b) Printed with a $15 \mu \mathrm{m}$ thick layer of graphene oxide on top. (c) The equivalent circuit of the sensor [112].

In practice, the modifications in the matching network due to the changes in the sensing element also affect the quality of the matching network. Therefore, the shifted resonance may not provide maximum power transfer to the RFID tag. As a result, based on the sensor's dynamic range, the read range, which is directly dependent on the strength of the interrogation signal received by the rectifier circuit, might be lower at some states of the sensor. This will eventually determine the actual read range of the RFID sensor. Moreover, since the sensor information is delivered through analog communication, only moderate accuracy is obtained. Furthermore, the shift in resonance requires a higher bandwidth for the sensor to operate. In contrast, the design is low cost as the sensor is passively integrated into the matching network. Chip-based RFID antenna resonance wireless sensors have been proposed operating within the read range of 3 to $5 \mathrm{~m}$ [33-37]. 


\subsubsection{Chip-Based Multi-Port Topology}

Keeping the read range of an RFID tag intact and unaffected by the addition of a sensing element is one of the main goals of research on RFID-based wireless sensors. Usually, the power-up signal reaching the RFID chip is the limiting factor in the read range of an RFID-based wireless sensor. As the reader is connected to a power source, it can provide a good amount of power. However, the effective isotropic radiated power (EIRP) is limited to $36 \mathrm{dBm}$ by the standards of RFID EPC-GEN 2 and cannot be increased above this level. On the other hand, the tag must also receive the minimum amount of power required to generate enough voltage to operate its circuitry. Therefore, any losses in the sensing element affect the read range of the RFID tag.

To ensure that the power-up signal reaches the RFID tag's rectifier without incurring any loss, there should be no lossy component added in its path. In the previous topology, we observed that the signal passing through the matching network undergoes some loss as the sensed value changes. To address this issue, another topology was recently proposed in which the sensing element was removed from the path of the signal and attached to the path of the backscattered signal. This was achieved by using a multi-port device that separates the incoming signal from the backscattered signal. A block diagram of this topology and a 3D plot of a sample design are shown in Figures 9 and 10, respectively.

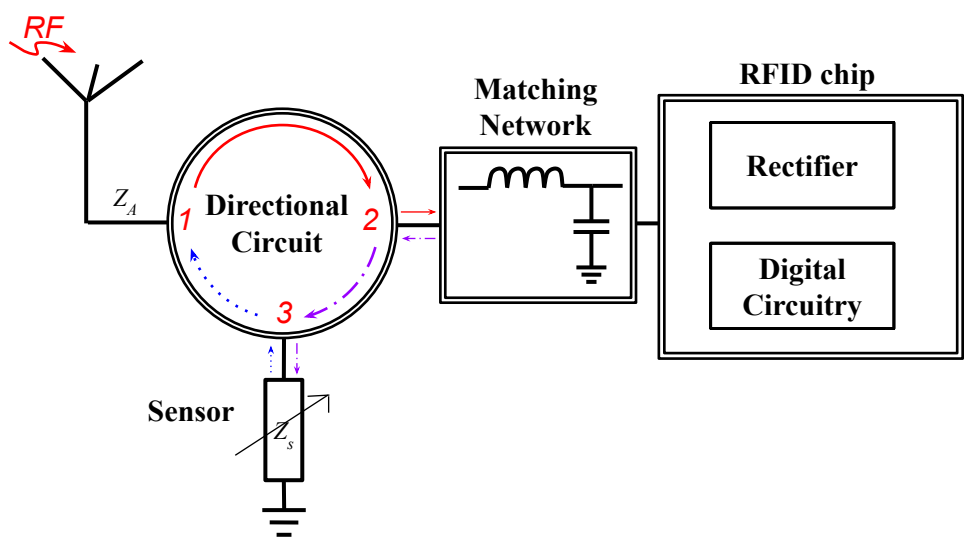

Figure 9. Block diagram of a chip-based multi-port wireless sensor.

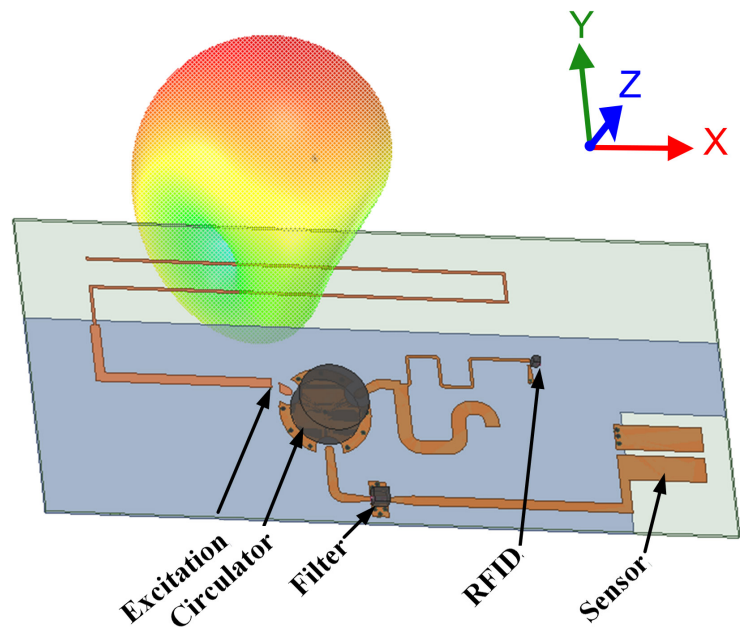

Figure 10. Three-dimensional model of a chip-based multi-port wireless sensor [113].

This topology ensures that the power-up signal reaches the RFID tag without any significant loss. The backscattered signal is sent to the sensing element where an additional phase delay is introduced. The sensor information in the phase can be easily extracted by the reader. Although having sensor circuit introduces extra loss in the backscattered 
signal, the reader is connected to a power source and can interpret and demodulate a fairly low-power signal. Therefore, this topology provides an improvement in terms of read range compared to the previous one in Section 3.2.1 simply by eliminating the sensing element from the power-up signal path. Since the sensor information is a hybrid of digital and analog communication, the required bandwidth is low. However, having a multi-port device requires components that may increase the cost by a few dollars. Sensors with medium accuracy operating at a range of $7 \mathrm{~m}$ have been reported in [39-41].

\subsubsection{Chip-Based Digitally Integrated Topology}

Another chip-based RFID topology is one in which the sensing element is attached to digital circuitry, which reads its value and sends the data digitally back to the reader [114]. To accomplish this, the incoming interrogation signal first energizes the rectifier circuit. After the required threshold level is achieved, the added digital circuitry in the IC uses a portion of this power to determine the sensed value.

One of the methods to design the digital circuitry is to have a phase-locked loop (PLL)-based sensor interface that compares the phase of two oscillators, where one of the oscillators is connected to a reference capacitor and the other is attached to the capacitive sensing element. Any change in the element introduces a phase difference between the two oscillators. This change is determined through the error port of the PLL. The amplitude of the error signal is directly related to the difference between the capacitance value of the reference capacitor and the element. The error signal is read by an on-chip ADC, which is then digitally concatenated to the tag's identity data and sent back to the reader through the backscattered signal [43]. A simple block diagram and a chip-level block diagram of the digitally integrated sensor are shown in Figures 11 and 12, respectively. The chip level block diagram includes details of a digitally integrated temperature sensor, which shows what components are required to design the sensor.

The main challenge in a chip-based digitally integrated sensor is having digital circuitry that operates at very low voltage and uses a minimum amount of power to read the sensed value with a suitable accuracy. This added circuitry can significantly reduce the read range of an RFID chip and can slightly increase its cost. Currently, sensors utilizing this topology have been demonstrated with read ranges of around 0.7-2.2 $\mathrm{m}$ [42,43]. It should be noted that, since the sensor information is communicated digitally, the accuracy is high and the bandwidth is the same as a regular RFID chip.

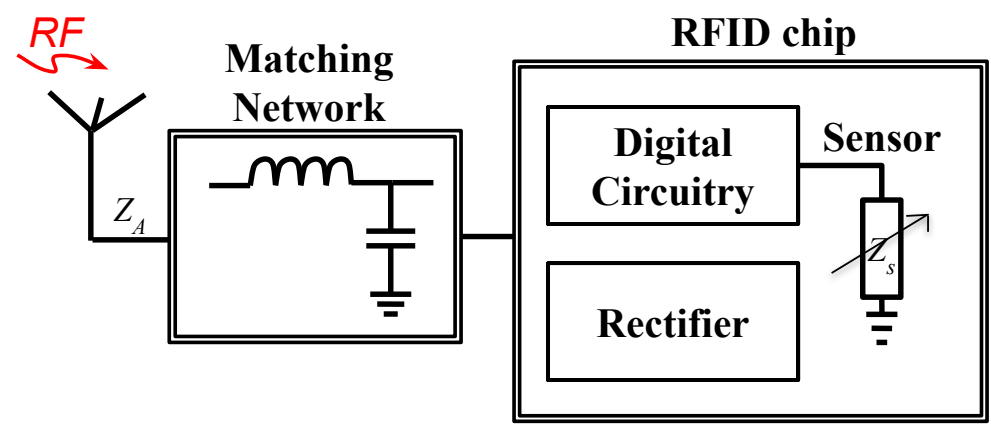

Figure 11. A simple block diagram of a chip-based digitally interfaced sensor. 


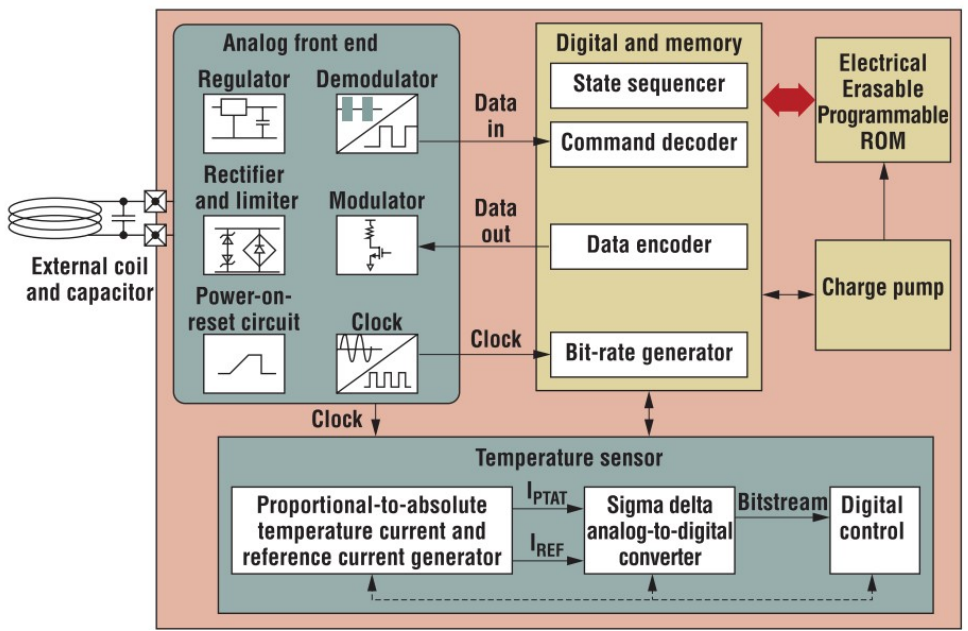

Figure 12. A chip-level block diagram of a chip-based digitally interfaced RFID sensor [23].

\subsubsection{Chip-Based Ambient Energy-Harvesting Topology}

To improve the read range of chip-based RFID sensors without adding a battery, harvesting the energy from an ambient source can be of help. There are multiple power sources that are ambient-solar power and indoor lights or RF signals from radio and TV stations, WiFi networks, and cellphone towers [44-47]. By attaching a small solar cell and/or by using a wide-band receiver that is capable of receiving RF signals from an ambient source, the overall energy received by an RFID-based wireless sensor can be tremendously increased. Therefore, without adding any battery, the read range of the sensor can be improved. A block diagram and a prototype of such a sensor tag are shown in Figures 13 and 14, respectively.

If the RFID chip operates on the principles of backscattering the transmitted signal, the limiting factor, in this case, is the reader's sensitivity, as follows. In RFID communication, a power-up signal faces two-way path loss and any losses inside the RFID tag, which can be antenna mismatch, sensing element loss, and RFID backscattering switch loss. In an ideal case where there is no power lost inside the tag and considering the maximum allowed EIRP of $36 \mathrm{dBm}$, with a receiver sensitivity of $-90 \mathrm{dBm}$ and a tag antenna gain of $3 \mathrm{~dB}$, the two-way path loss at $915 \mathrm{MHz}$ allows for $66 \mathrm{~dB}$ path loss in one direction. This corresponds to around $52 \mathrm{~m}$ of distance between the reader and the tag. Here, we considered that the RFID tag is obtains enough energy from an ambient source to fully power-up its internal circuitry and the digital circuitry of the sensor. Sensors utilizing this topology, using only solar cells, have shown a read range of around $15 \mathrm{~m}$ [20]. Since the sensor information is sent digitally, the accuracy is high. Furthermore, the bandwidth is the same as a regular RFID chip, whereas the cost increases due to the added solar panels.

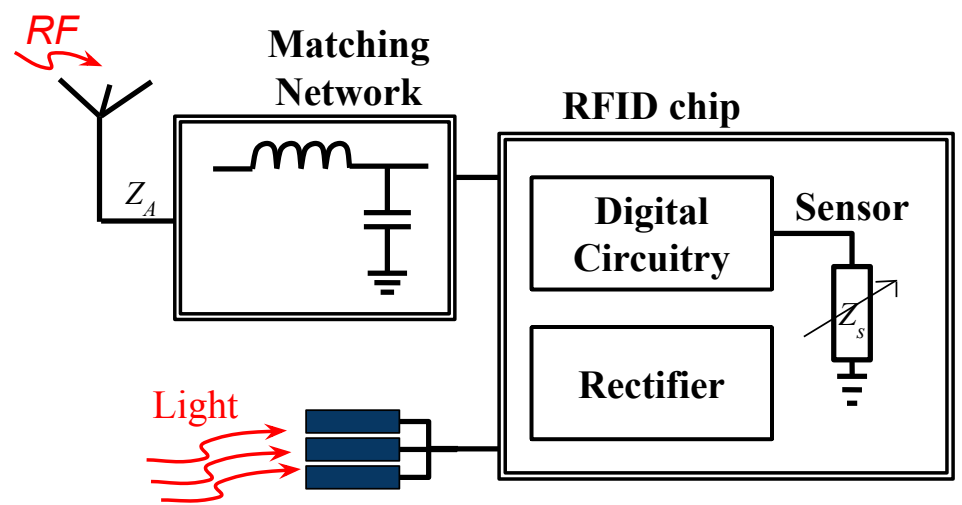

Figure 13. Block diagram of a chip-based ambient (light) energy-harvesting wireless sensor. 


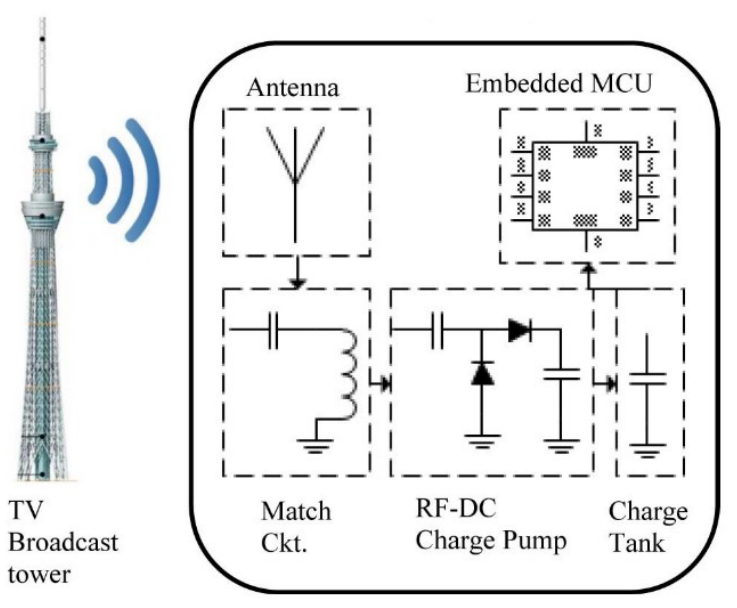

Figure 14. Prototype of a chip-based ambient (RF) energy-harvesting wireless sensor [45].

\subsection{Topology Summary}

A comparison of all five aforementioned RFID-based sensor topologies is presented in Table 1. The sensors are compared against their cost, complexity, bandwidth, anti-collision support, dense deployment support, and range. Each type comes with strengths and weaknesses. If a low-cost solution in an uncluttered environment is required, chip-lessbased RFID wireless sensors are an excellent solution. However, if multiple parameter sensing measurements in a highly dense area are required, chip-based solutions may be preferred. Topology in the chip-based solution may be selected based on cost and read-range requirements.

Table 1. Comparison of the five RFID-based sensor topologies discussed.

\begin{tabular}{lccccc}
\hline Parameter & $\begin{array}{c}\text { Chip-Less } \\
{[8,29,95,103-106]}\end{array}$ & $\begin{array}{c}\text { Antenna } \\
\text { Resonance } \\
{[33-37]}\end{array}$ & $\begin{array}{c}\text { Multi-Port } \\
\text { Architecture } \\
{[39-41]}\end{array}$ & $\begin{array}{c}\text { Digitally } \\
\text { Integrated } \\
{[42,43]}\end{array}$ & $\begin{array}{c}\text { Ambient Energy } \\
\text { Harvesting [20] }\end{array}$ \\
\hline Cost & Very Low & Low & Moderate & Moderate & High \\
Complexity & Very low & Moderate & Low & Low & Moderate \\
Bandwidth required & $\sim \mathrm{MHz}$ & $\sim \mathrm{MHz}$ & $\sim \mathrm{kHz}$ & $\sim \mathrm{kHz}$ & $\sim \mathrm{kHz}$ \\
Anti-collision & $\mathrm{No}$ & Yes & Yes & Yes & Yes \\
Dense deployment & $\mathrm{No}$ & Yes & Yes & Yes & Yes \\
Range $(\mathrm{m})$ & $2-30$ & $3-5$ & $7-10$ & $1-2$ & $5-10$ \\
\hline
\end{tabular}

\section{Implementation and Testing}

The theory of five RFID-based wireless sensor topologies has been discussed in detail in the previous section. There are different methods to implement these topologies. Here, we discuss a practical implementation of each. Each example is considered based on its complexity, cost, read range, and accuracy.

\subsection{Chip-Less RFID Sensor Implementation \\ Example of a Chip-Less RFID Humidity Sensor}

Humidity is one of the key elements that is required in controlled amounts in different environments. In homes, extreme dryness can cause deterioration to human skin, whereas for plants and animals, it determines whether they can thrive in the environment. Moreover, it is an important factor that determines if specific electronics and electrical equipment are safe to be used in a given environment, as very high humidity levels may cause a short circuit. Therefore, humidity is an important parameter that needs to be gauged. 
Humidity is often measured as Relative Humidity (RH), which is a ratio of the partial pressure of water vapors available in the air to the saturation vapor pressure of the air. To determine this ratio, polymers that absorb water molecules, such as Polyvinyl Alcohol (PVA), are used as a sensing element on a capacitor. As the vapor pressure increases, the polymer absorbs more and more water. As a result, the average permittivity of the capacitor increases, which eventually raises its capacitance.

To form a chip-less RFID-based wireless humidity sensor, Amin et al. in [95] combined a simple multiple slot resonator with a PVA coated ELC resonator. The multiple slots in the design are used to obtain resonance at different frequencies so that the sensor node could be identified. This was achieved by designing slots of different lengths on a patch without a ground plane. The ELC resonator was separately coated with PVA so that only its resonance changes with the change in the humidity. The layout and fabricated circuit are shown in Figures 15 and 16, respectively.

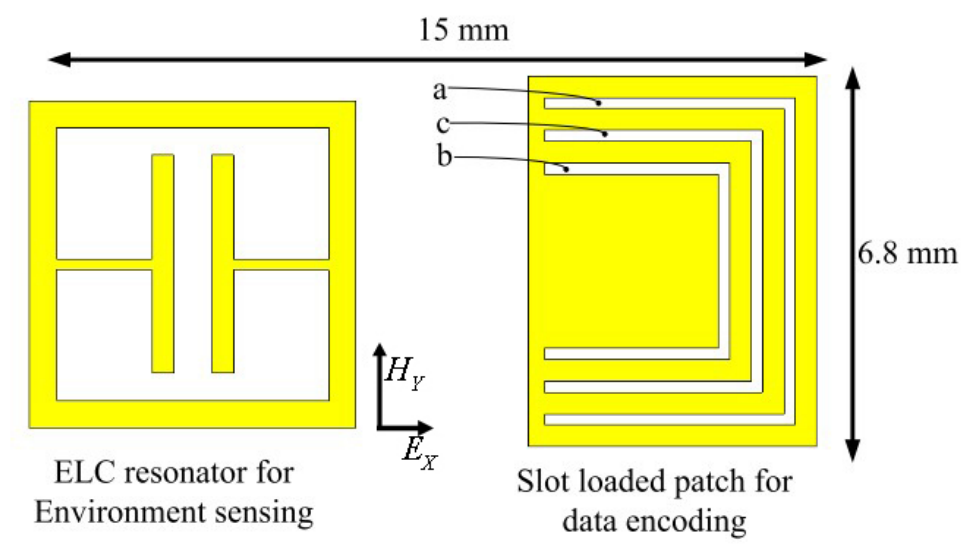

Figure 15. The layout of the chip-less RFID tag humidity sensor [95].
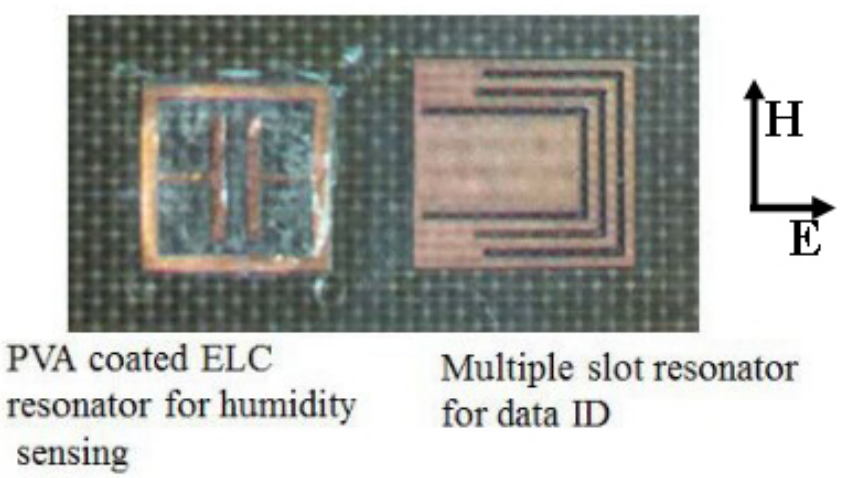

Figure 16. Fabricated circuit of the chip-less RFID tag humidity sensor [95].

To evaluate the design, tests were performed in a humidity-controlled chamber. Two horn antennas connected to a Vector Network Analyzer (VNA) were used to study the resonance at varying humidity levels. The wireless sensor was placed between the two antennas, and a frequency sweep was performed using the VNA. The setup is shown in Figure 17.

The complex transmission coefficient (S21) at different humidity levels was recorded, and the data are shown in Figure 18a. Three resonance points occurring due to the slots a, $\mathrm{b}$, and $\mathrm{c}$ are labeled with their corresponding resonances that help in identifying the tag. It can be seen that these resonances are little affected by the change in humidity. However, the resonance of the sensor, which is around $6.5 \mathrm{GHz}$, varies with the change in humidity levels. A detailed plot of the sensor response is shown in Figure 18b. 


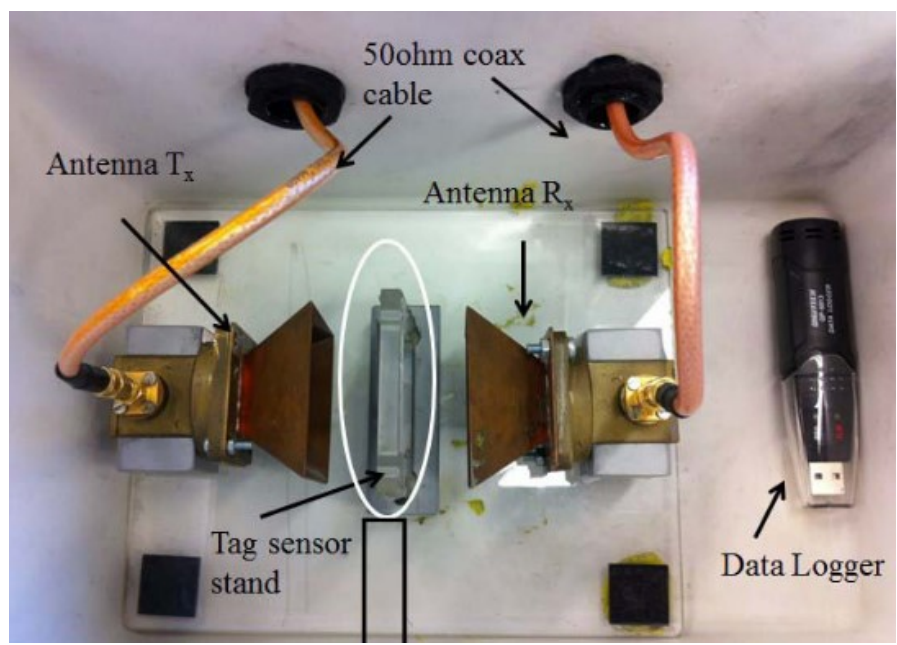

Figure 17. The test setup of the chip-less RFID tag humidity sensor [95].

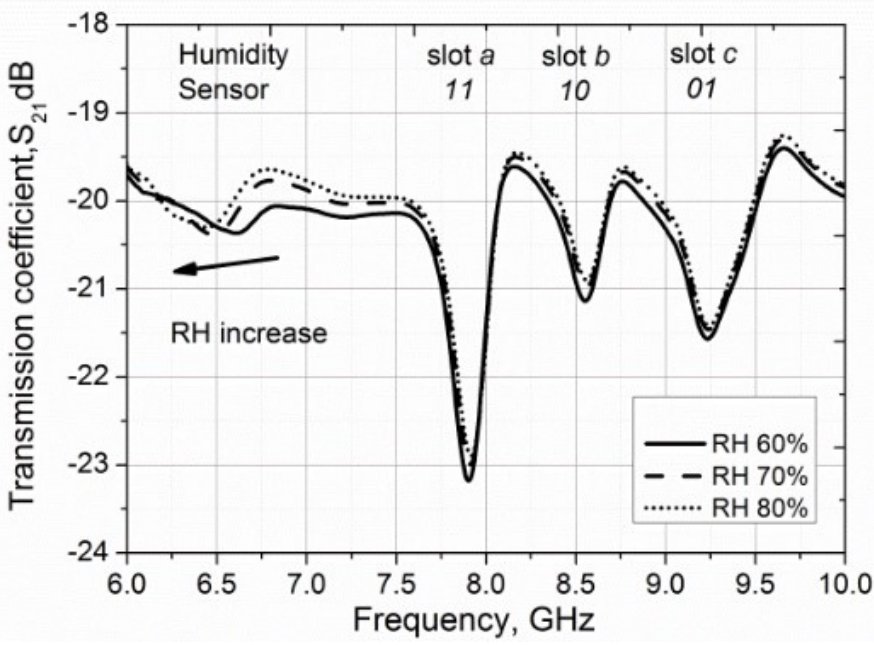

(a)

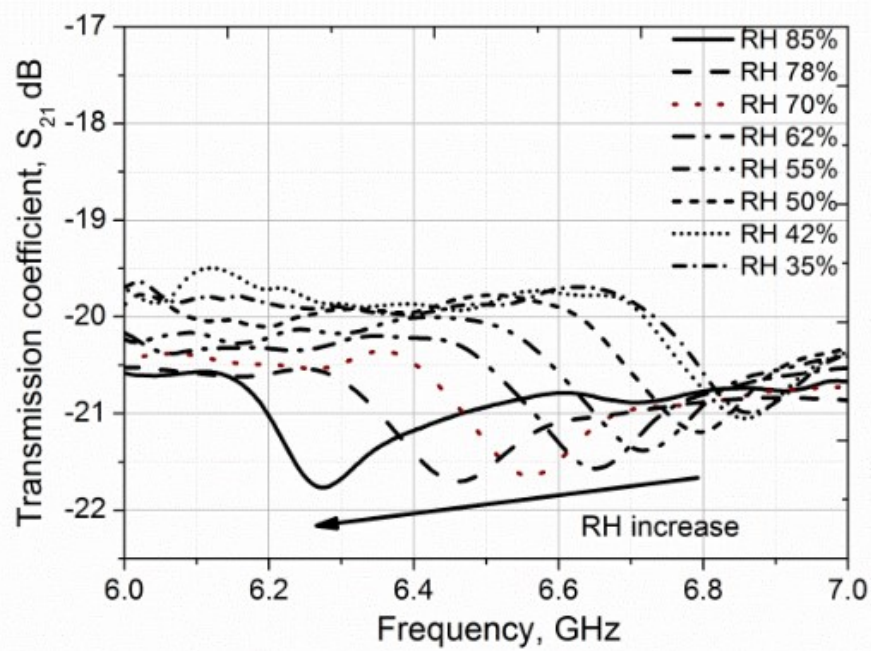

(b)

Figure 18. (a) Measured transmission coefficient (calibrated) (S21) versus frequency for the chip-less RFID humidity sensor with PVA coating. (b) Detailed experimental results with ELC resonator as a humidity sensor [95]. 
The example combines chipless identification and sensing together. Due to its passive nature, the cost is very low. Moreover, since there is no chip required in the sensor, the read range depends on the reader and clutter around the sensor. Hence it can easily go up to a few meters. However, the accuracy deteriorates as the signal level reaches close to the noise level of the reading device.

\subsection{Example of a Chip-Based Antenna Resonance}

Body movement monitoring is an important observation in medical treatments, athletics, or the army. In medical treatment, monitoring may be required where a patient has undergone surgery and must stretch their body parts to enhance muscle formation. Doctors need to determine the extent of the body movement of their patients. This is achieved by attaching sensors to the patients' bodies that help to monitor their movements.

In [115], Mehmood et al. proposed an RFID-based passive strain sensor design that is easily integrated into clothing. This integration allows for monitoring strain on the sensor wirelessly. As a result, movements of different parts of the body are easily determined without attaching any wires, which may otherwise introduce hindrance to the mobility of the patient.

To design a passive strain sensor, a stretchable antenna was designed so that its resonance changes as it is stretched along its length. The antenna was designed using a conductive textile material, which was easily integrated into a shirt. Moreover, a nonstretchable antenna was also designed and attached to the shirt to act as a reference. The model and fabricated circuits are shown in Figures 19 and 20, respectively.

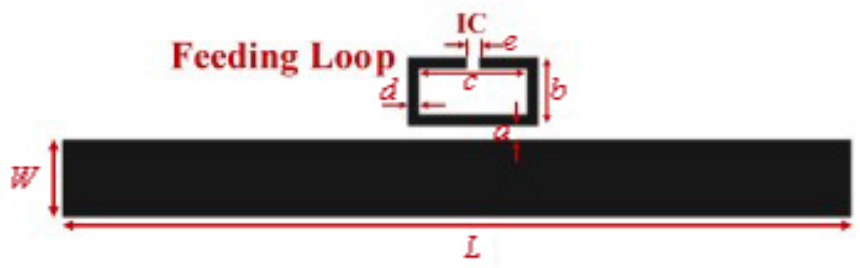

\begin{tabular}{|c|c|c|c|c|c|c|}
\hline$a$ & $b$ & $c$ & $d$ & $e$ & $L$ & $W$ \\
\hline 2.5 & 11.3 & 21.6 & 1.9 & 2 & 135 & 12.6 \\
\hline
\end{tabular}

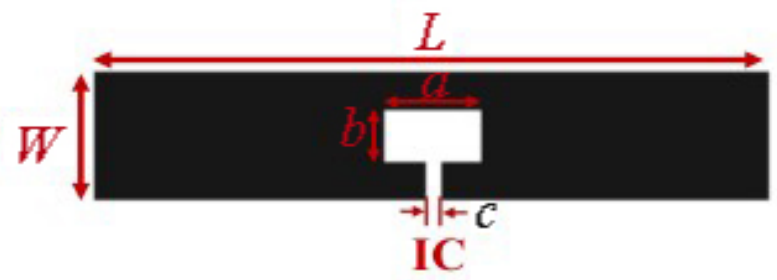

\begin{tabular}{|c|c|c|c|c|}
\hline$a$ & $b$ & $c$ & $L$ & $W$ \\
\hline 14.3 & 8.125 & 2 & 100 & 20 \\
\hline
\end{tabular}

Figure 19. The layout of a chip-based antenna resonance controlled strain sensor [115].

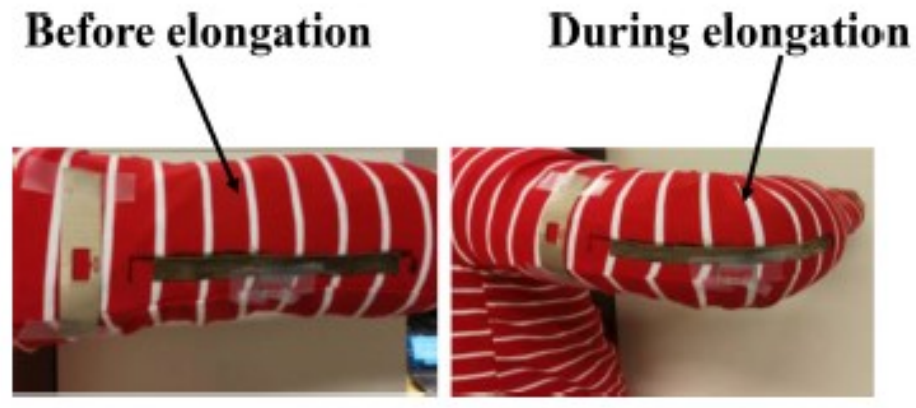

Figure 20. Implemented circuit of the strain sensor on a T-shirt [115]. 
To measure the sensed value, a general RFID reader was used that reads the ID of the tag and the amplitude of the backscattered signal. The simultaneous reading of backscattered signals of the reference tag and the sensitive tag allows for determining the sensed value by calculating the difference in their RCS. The results in Figure 21 show the amplitude of the backscattered signal for a straight and a bent arm.

The results show how a simple chip-based antenna resonance varying sensor can be used to determine the stress on a wearable item that could eventually help determine the body movement of a patient. The cost is low since it only requires a single RFID chip, which costs a few cents. The reported range of this wireless sensor in a working environment is around $1 \mathrm{~m}$. The deterioration is mainly because of the losses in the sensor, which directly affect its read range. The accuracy is low because the magnitude of the backscattered signal can be easily affected by ambient noise.

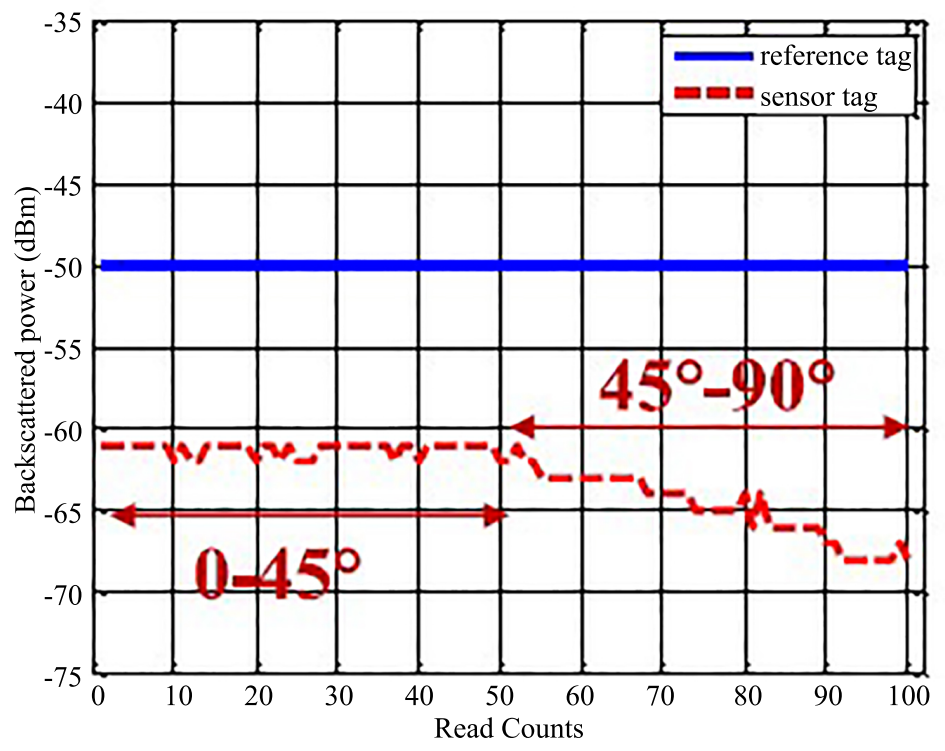

Figure 21. The results of a strain sensor showing varying RCS at different strain levels [115].

\subsection{Example of a Multi-Port Chip-Based Battery-Less}

Liquid level detection is extremely useful in a wide variety of applications. For example, in houses, a timely warning of flooding can help avoid huge losses. Additionally, in medical treatments, patients are given medications for which determining the rate or amount of the dose that is being delivered to the patient is an important parameter. Using a battery-less and wireless liquid level detector can be very helpful in both applications.

Different fluids have a different amount of conductivity. Using this nature of fluids, liquid levels can easily be determined by making simple probes that are either conductive or capacitive. As the water level rises, the conduction or capacitance of the sensing element varies. In [39,41], Khalid et al. used similar electrodes for a sensing element in which the conduction and capacitance varied with the change in the liquid levels.

Using a multi-port chip-based passive wireless sensor, the incoming signal from the RFID reader is directly sent to the RFID tag. When the tag responds by backscattering the incoming signal, the backscattered signal is routed to the flood sensing element using a simple circulator. The model and circuit are shown in Figures 22 and 23, respectively. The attached element adds a phase delay to the backscattered signal based on its capacitance, which depends on the liquid level inside the container. This delay is easily determined by using a reader IQ-based demodulator. The results in Figure 24 show how the phase of the backscattered signal changes as the level of fluid increases or decreases with time.

Since a circulator and an RFID chip are required, the cost of this design is moderate. The incoming signal reaches the tag without any loss from the sensing element; therefore, the RFID tag's read range remains unaffected by the addition of the element. 
The demonstrated range of this sensor was $7 \mathrm{~m}$. The sensor information is sent through phase modulation, and the accuracy is in the medium range.

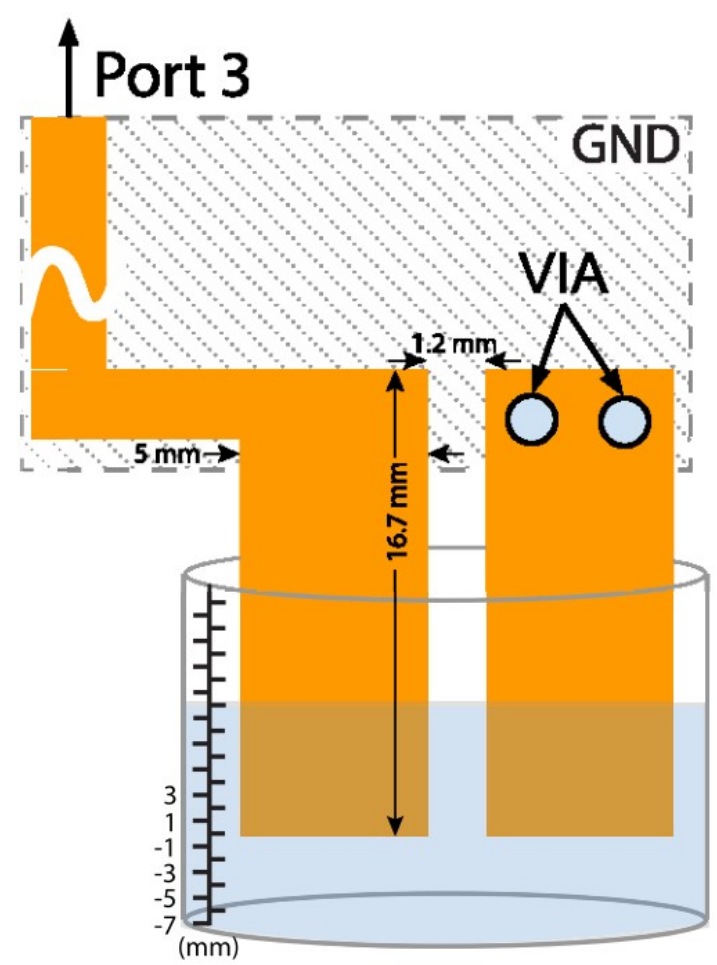

Figure 22. The layout of chip-based multi-port flood sensor [39].

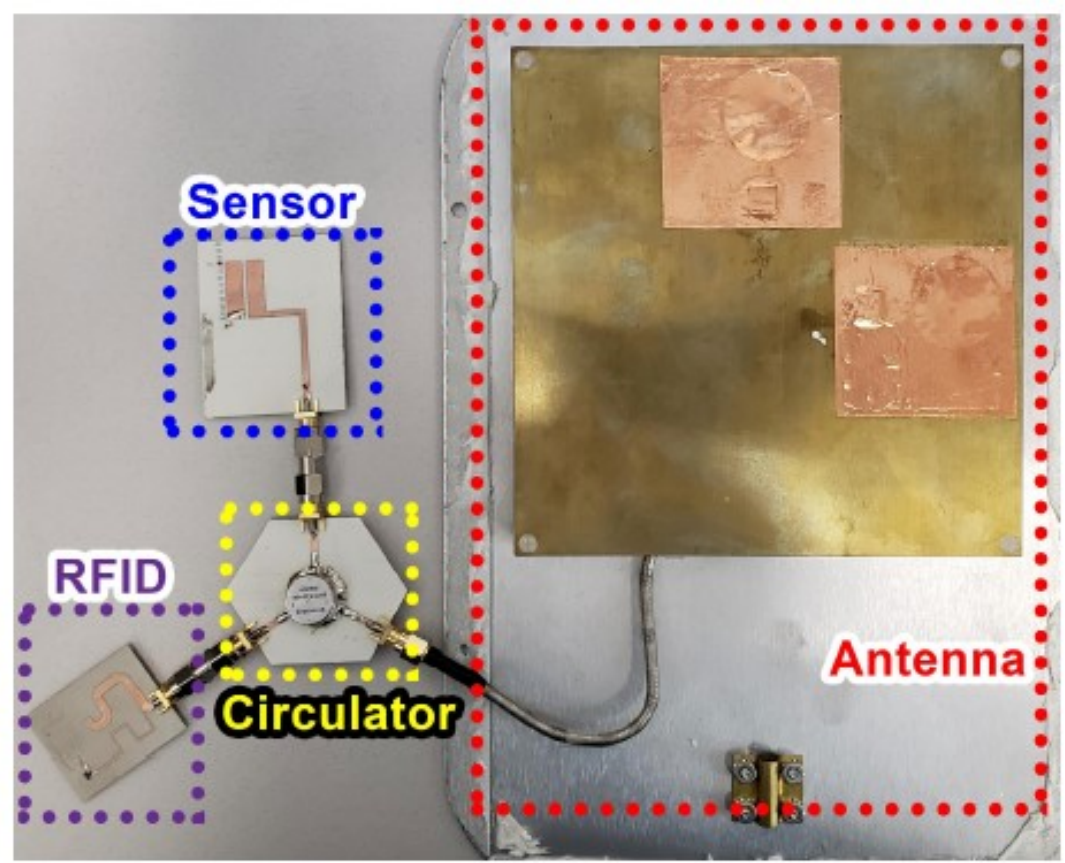

Figure 23. Implemented circuit of the flood sensor [39]. 


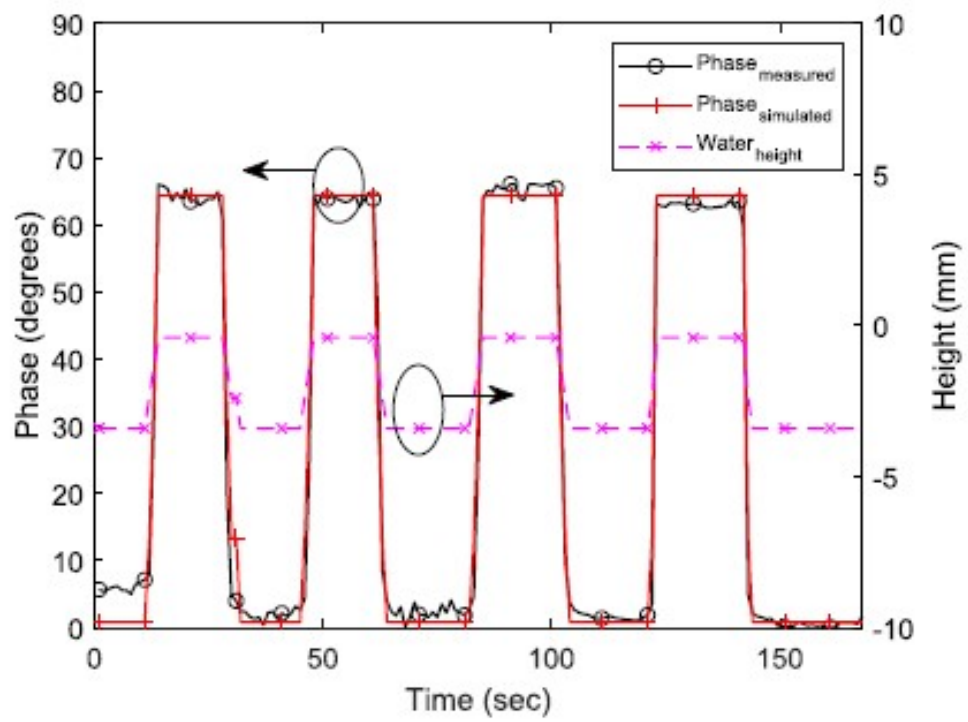

Figure 24. Results of the flood sensor showing varying phases of the backscattered signal at different water levels [39].

\subsection{Example of a Chip-Based Digitally Integrated}

In all of the aforementioned topologies, the sensing element integrated into an RFID tag must be responsive at the frequency of operation. Usually, sensors available in the market operate up to a few $\mathrm{kHz}$. The ability to use off-the-shelf sensors can be very helpful where wireless range is not a concern. Moreover, there is a wide range of sensors, such as temperature sensors and force sensors, that operate at low frequencies and are easily available in the market. In [42], Fernandez et al. demonstrated the use of RFIDs that digitally integrate sensors by combining a force sensor and by using an in-built temperature sensor.

The RFID tag used for the demonstration was an SL900A RFID chip (AMS AG, Austria), which is compatible with EPC-Gen 2 RFID standard [116]. This RFID tag incorporates an on-chip A/D converter and a voltage supply. These components can be used to determine the attributes of an external sensor to record its value. This value is digitally sent back to the reader. The designed circuit layout and the fabricated circuit are shown in Figures 25 and 26, respectively.

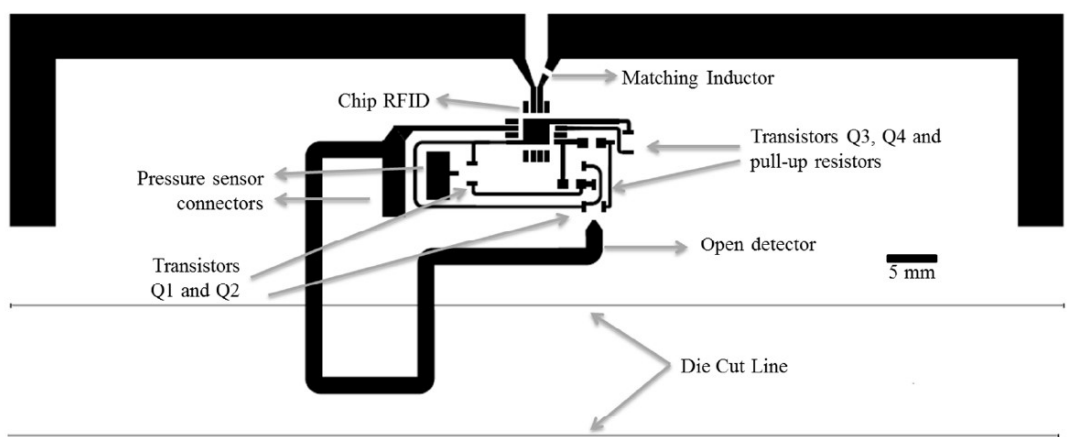

Figure 25. Layout of a chip-based digitally integrated force sensor [42]. 


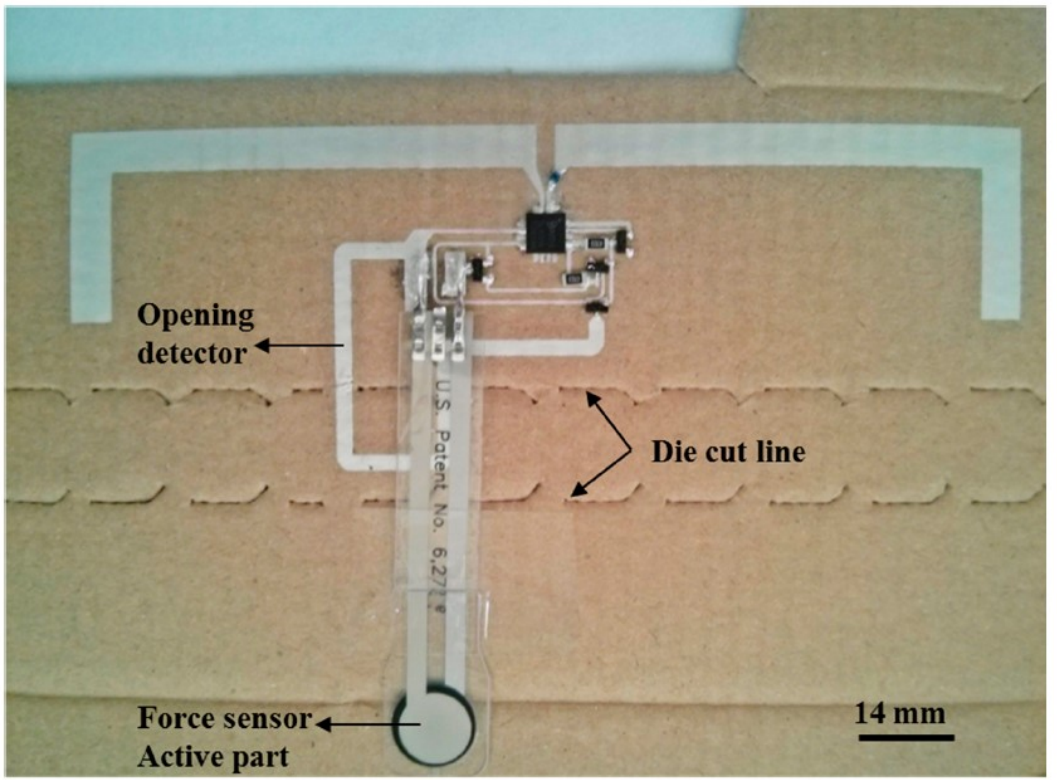

Figure 26. Implemented circuit of the force sensor [42].

The built-in temperature sensor provides a resolution of around $0.23{ }^{\circ} \mathrm{C}$ and can be used from $-89.3^{\circ} \mathrm{C}$ to $147.9^{\circ} \mathrm{C}$. To analyze the performance of the external sensor ports, a force sensor was attached to a container. The force sensor presents a resistance in the range of $\mathrm{M} \Omega$ when there is no mass attached to it, whereas its resistance decreases as the mass increases. The sensor was tested with weights spanning the range from $1 \mathrm{~kg}$ to $4 \mathrm{~kg}$. Multiple values were recorded with single and dual setup increments and decrements to observe the hysteresis of the sensor. A 3\% error was found, which was within the error of the force sensor. The results are shown in Figure 27.

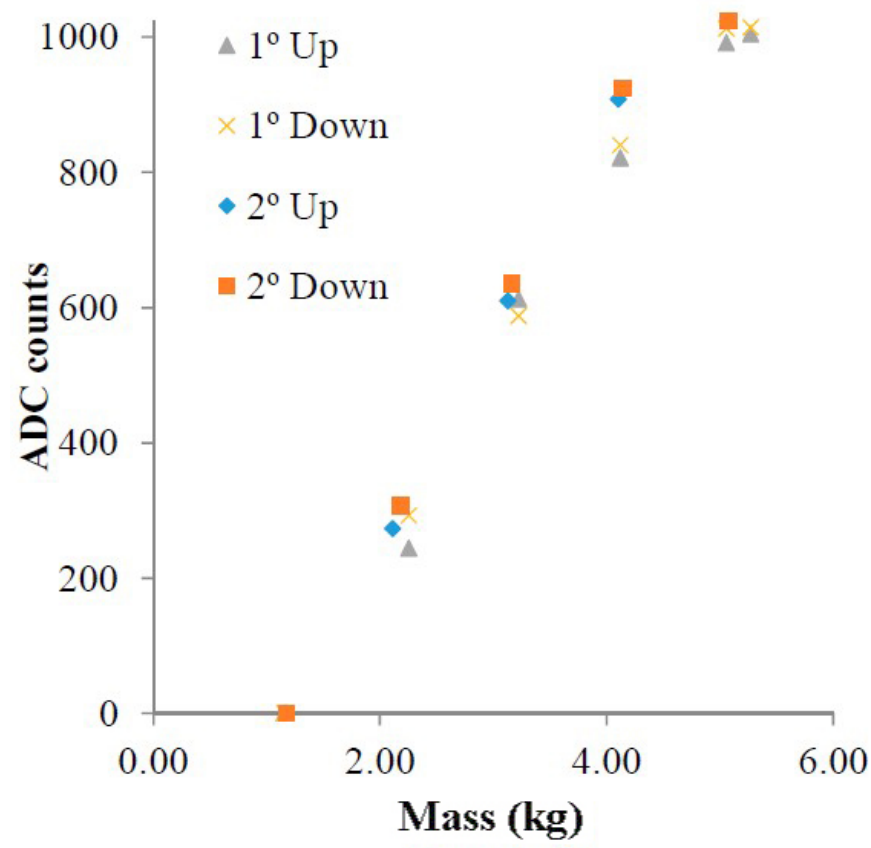

Figure 27. The results of a force sensor showing varying ADC count transmitted by the sensor [42]. $\mathrm{X}^{\circ}$ up/down shows $\mathrm{X} \mathrm{kg}$ change in weight to observe the sensor's hysteresis. 
Although the design can be simple and cost effective, the use of an additional ADC to record the sensor value results in a huge amount of power being sacrificed in this case. Therefore, when working as a battery-less wireless sensor, the maximum range reported for this RFID-based wireless sensor is only $1.1 \mathrm{~m}$. However, the accuracy is high because the data is sent to the reader through digital modulation techniques.

\subsection{Example of Chip-Based Ambient Energy Harvesting}

All of the previously discussed wireless sensors harvested energy using power that was delivered from the interrogator. Therefore, their range is limited, and they perform well only in short- to mid-range applications. To improve the range, energy harvesting from an ambient source can also be introduced. There are photovoltaic (PV) and non-PV energy sources that are ambient and that can be used for energy harvesting.

With the widespread availability of PV energy through indoor and outdoor lights, PV-based energy harvesting is a very promising technique. In [20], a PV-based RFID sensor that can detect temperature and transmit the information wirelessly has been demonstrated. In this design, an EM 4325 IC from EM Microelectronics was used to incorporate a built-in temperature sensor connected to the internal sensor controller that converts the sensed value from analog to digital. This digital value is communicated back to the reader through backscattering.

The RFID tag used in this design allows for connecting an external battery to operate it as an active sensor. However, since the goal is to have a battery-less wireless sensor, PV cells were attached to these ports. A supercapacitor of $10 \mathrm{~F}$ was also attached in parallel to the PV cells to harvest the received energy. This increased the cost of the sensor. The model and the fabricated circuit are shown in Figures 28 and 29, respectively. Although the communication/tracking range of up to $18 \mathrm{~m}$ was shown, the maximum recorded range, after enabling the integrated sensor, was around $6 \mathrm{~m}$. The results are shown in Figure 30. High accuracy was achieved as the sensor data is digitally communicated back to the reader.

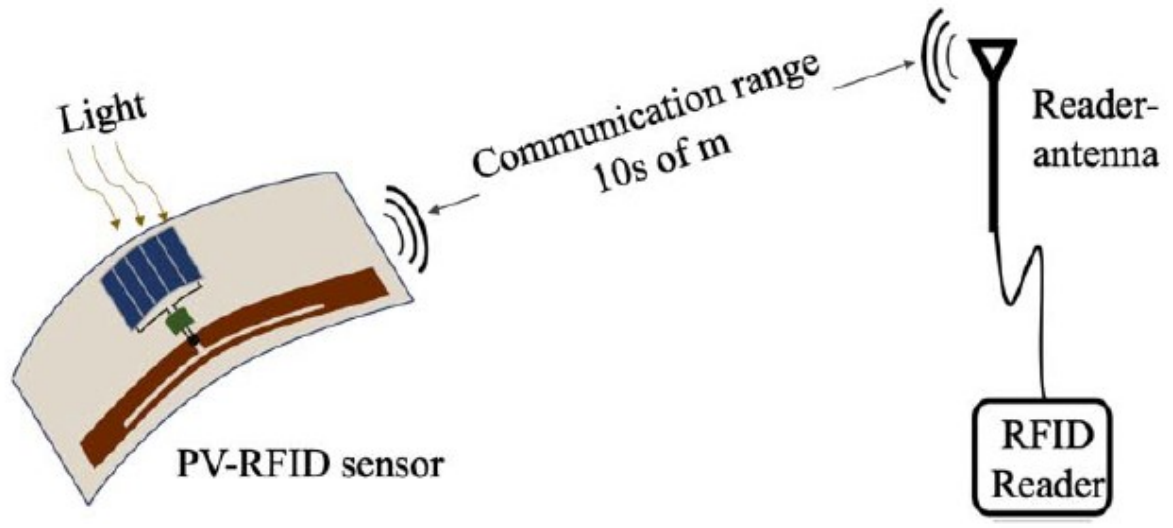

Figure 28. Model of the chip-based ambient energy-harvesting temperature sensor [20]. 


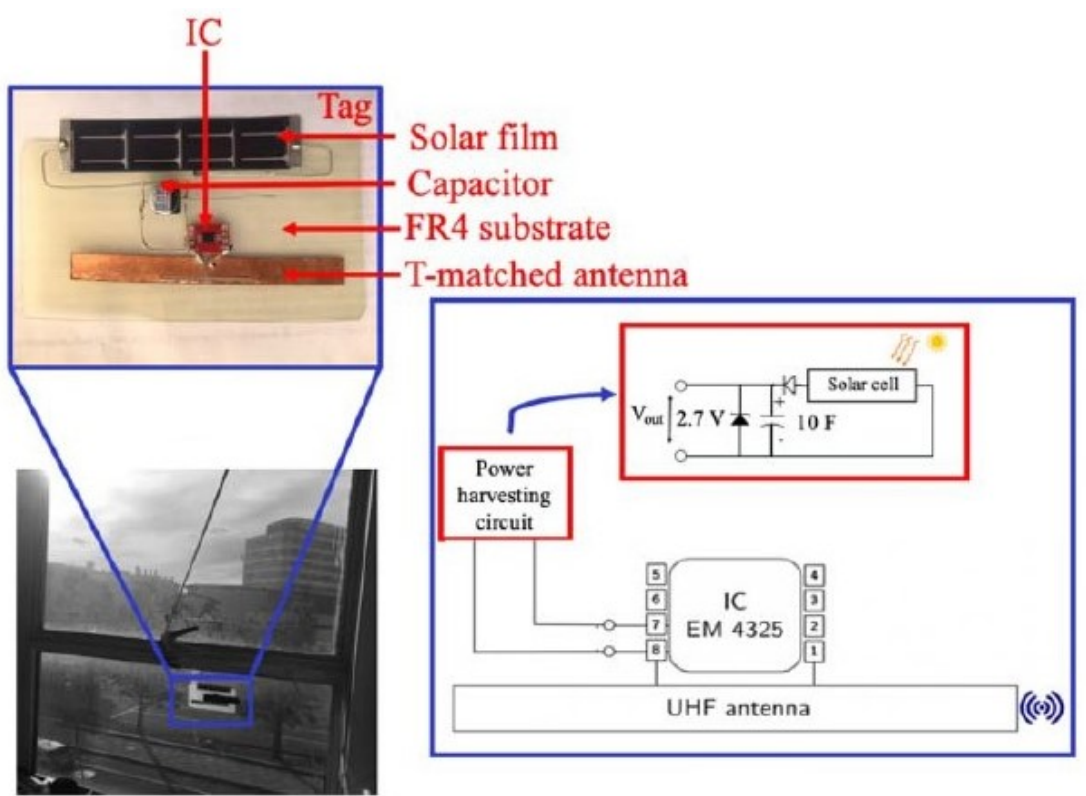

Figure 29. Implemented circuit of the temperature sensor [20].

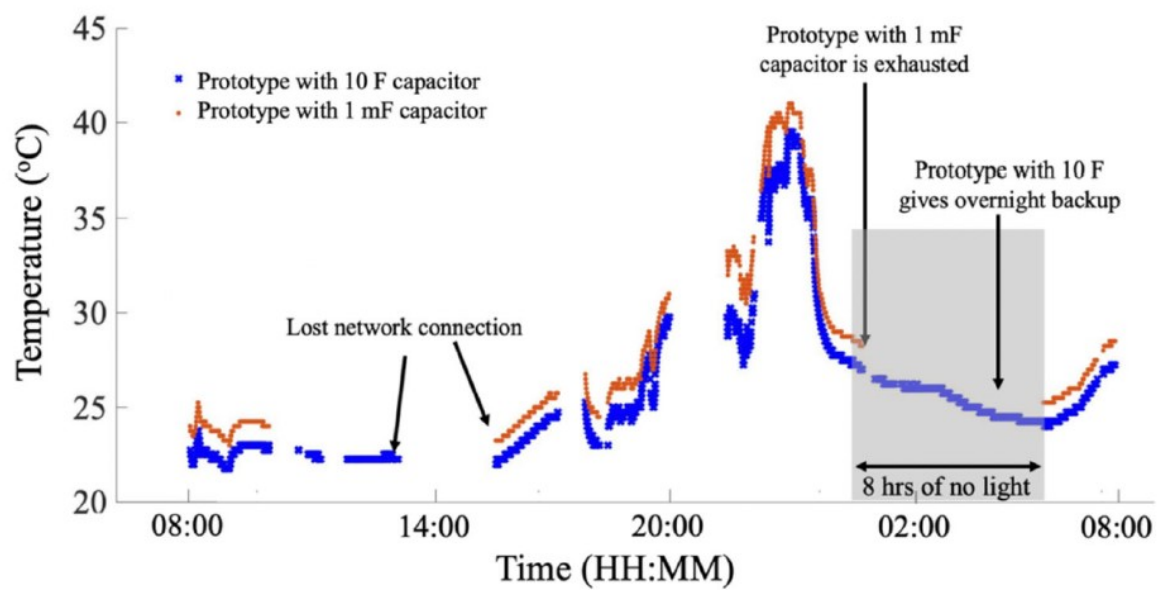

Figure 30. Results of the temperature sensor showing varying temperature and performance recorded for one full day [20].

\section{Future Directions}

Although a vast amount of research has already been carried out on battery-less RFID-based wireless sensors, it is clear that a great deal of potential remains for future discoveries. Among the several sensor parameters discussed in this review (e.g., read range, accuracy, cost, and size), it is evident that an improvement in sensor read ranges is still of prime interest to the community. By looking at the aforementioned topologies, we can deduce that a combination of chip-based multi-port and ambient energy harvesting can yield a much higher range-theoretically, up to $50 \mathrm{~m}$.

We also saw that the size and cost of the multi-port topology are not optimal but may be significantly improved through the use of highly miniaturized antennas employing novel matching techniques to enable compact, long-range RFID-based battery-less wireless sensors $[60,61]$.

If accuracy is a concern, digitally integrated sensor topologies with ambient energy harvesting show a great deal of promise. To increase the read range, ambient PV and RF energy may be combined. Moreover, the fabrication of the rectifier circuitry must be engineered to achieve better results. This involves using detailed models of the fabrication process that produce more accurate results and higher consistencies between different batches. 
Lastly, we observed that there is a scarcity of sensor components operating in the low $\mathrm{GHz}$ range. Research that seeks high-frequency sensing component designs is also needed. This will allow RFID-based battery-less sensors to be used in many new applications, readying them for deployment in the future Internet-of-Things.

\section{Conclusions}

An in-depth review of battery-less RFID-based wireless sensors was conducted. All of the different components of an RFID sensor, including the antenna, rectifier, digital circuit, and sensing element, were discussed in detail. Various topologies that use the components in different ways were investigated. It was observed how the utilization of the limited power and arrangements of the components can affect the read range of a battery-less RFID-based wireless sensor. Real-world implementations of humidity, flood, force, and temperature sensors were discussed. It was noted that chip-based topologies provide the maximum read range with dense deployment capabilities. Finally, some potential future directions for battery-less RFID-based wireless sensors were presented.

Author Contributions: Conceptualization, methodology, formal analysis, investigation, and writingoriginal draft preparation, N.K.; writing - review and editing, supervision, R.M. and A.K.I. All authors have read and agreed to the published version of the manuscript.

Funding: This work was supported by the NSERC-AITF industrial research chair program.

Institutional Review Board Statement: Not applicable.

Informed Consent Statement: Not applicable.

Data Availability Statement: Not applicable.

Acknowledgments: The authors thank Zachary Kwong for his valuable comments, thus improving the quality of this paper.

Conflicts of Interest: The authors declare no conflict of interest. Moreover, the funders had no role in the design of the study; in the collection, analyses, or interpretation of data; in the writing of the manuscript; or in the decision to publish the results.

\section{References}

1. Wollschlaeger, M.; Sauter, T.; Jasperneite, J. The future of industrial communication: Automation networks in the era of the internet of things and industry 4.0. IEEE Ind. Electron. Mag. 2017, 11, 17-27. [CrossRef]

2. Sisinni, E.; Saifullah, A.; Han, S.; Jennehag, U.; Gidlund, M. Industrial internet of things: Challenges, opportunities, and directions. IEEE Trans. Ind. Inform. 2018, 14, 4724-4734. [CrossRef]

3. Mc Gee, K.; Anandarajah, P.; Collins, D. Current Progress towards the Integration of Thermocouple and Chipless RFID Technologies and the Sensing of a Dynamic Stimulus. Micromachines 2020, 11, 1019. [CrossRef] [PubMed]

4. Roberts, C.M. Radio frequency identification (RFID). Comput. Secur. 2006, 25, 18-26. [CrossRef]

5. Landt, J. The history of RFID. IEEE Potentials 2005, 24, 8-11. [CrossRef]

6. Hunt, V.D.; Puglia, A.; Puglia, M. RFID: A Guide to Radio Frequency Identification; John Wiley \& Sons: Hoboken, NJ, USA, 2007.

7. Want, R. Enabling ubiquitous sensing with RFID. Computer 2004, 37, 84-86. [CrossRef]

8. Cook, B.S.; Vyas, R.; Kim, S.; Thai, T.; Le, T.; Traille, A.; Aubert, H.; Tentzeris, M.M. RFID-based sensors for zero-power autonomous wireless sensor networks. IEEE Sens. J. 2014, 14, 2419-2431. [CrossRef]

9. Yang, L.; Rida, A.; Tentzeris, M.M. Design and development of radio frequency identification (RFID) and RFID-enabled sensors on flexible low cost substrates. Synth. Lect. RF/Microw. 2009, 1, 1-89. [CrossRef]

10. Akbari, S. Energy harvesting for wireless sensor networks review. In Proceedings of the 2014 Federated Conference on Computer Science and Information Systems, Warsaw, Poland, 7-10 September 2014; Volume 2, pp. 987-992. [CrossRef]

11. Muratkar, T.S.; Bhurane, A.; Kothari, A. Battery-less internet of things-A survey. Comput. Netw. 2020, 180, 107385. [CrossRef]

12. Kim, S.; Mariotti, C.; Alimenti, F.; Mezzanotte, P.; Georgiadis, A.; Collado, A.; Roselli, L.; Tentzeris, M.M. No Battery Required: Perpetual RFID-Enabled Wireless Sensors for Cognitive Intelligence Applications. IEEE Microw. Mag. 2013, 14, 66-77. [CrossRef]

13. Weglarski, M.; Jankowski-Mihułowicz, P. Factors affecting the synthesis of autonomous sensors with RFID interface. Sensors 2019, 19, 4392. [CrossRef] [PubMed]

14. Zhang, J.; Tian, G.Y.; Marindra, A.M.; Sunny, A.I.; Zhao, A.B. A review of passive RFID tag antenna-based sensors and systems for structural health monitoring applications. Sensors 2017, 17, 265. [CrossRef] 
15. Marrocco, G.; Amato, F. Self-sensing passive RFID: From theory to tag design and experimentation. In Proceedings of the 2009 European Microwave Conference (EuMC), Rome, Italy, 29 September-1 October 2009; pp. 1-4.

16. Ferdous, R.M.; Reza, A.W.; Siddiqui, M.F. Renewable energy harvesting for wireless sensors using passive RFID tag technology: A review. Renew. Sustain. Energy Rev. 2016, 58, 1114-1128. [CrossRef]

17. Ma, S.; Pournoori, N.; Sydänheimo, L.; Ukkonen, L.; Björninen, T.; Georgiadis, A. A Batteryless Semi-Passive RFID Sensor Platform. In Proceedings of the 2019 IEEE International Conference on RFID Technology and Applications (RFID-TA), Pisa, Italy, 25-27 September 2019; pp. 171-173.

18. Rida, A.; Yang, L.; Tentzeris, M.M. RFID-Enabled Sensor Design and Applications; Artech House: Norwood, MA, USA, 2010.

19. Merenda, M.; Felini, C.; Della Corte, F.G. Battery-less smart RFID tag with sensor capabilities. In Proceedings of the 2012 IEEE International Conference on RFID-Technologies and Applications (RFID-TA), Nice, France, 5-7 November 2012; pp. 160-164.

20. Kantareddy, S.N.R.; Mathews, I.; Bhattacharyya, R.; Peters, I.M.; Buonassisi, T.; Sarma, S.E. Long range battery-less PV-powered RFID tag sensors. IEEE Internet Things J. 2019, 6, 6989-6996. [CrossRef]

21. Zhang, J.; Periaswamy, S.C.; Mao, S.; Patton, J. Standards for passive UHF RFID. GetMobile Mob. Comput. Commun. 2020, $23,10-15$. [CrossRef]

22. Yi, X.; Wu, T.; Wang, Y.; Leon, R.T.; Tentzeris, M.M.; Lantza, G. Passive wireless smart-skin sensor using RFID-based folded patch antennas. Int. J. Smart Nano Mater. 2011, 2, 22-38. [CrossRef]

23. Opasjumruskit, K.; Thanthipwan, T.; Sathusen, O.; Sirinamarattana, P.; Gadmanee, P.; Pootarapan, E.; Wongkomet, N.; Thanachayanont, A.; Thamsirianunt, M. Self-powered wireless temperature sensors exploit RFID technology. IEEE Pervasive Comput. 2006, 5, 54-61. [CrossRef]

24. Vaz, A.; Ubarretxena, A.; Zalbide, I.; Pardo, D.; Solar, H.; Garcia-Alonso, A.; Berenguer, R. Full passive UHF tag with a temperature sensor suitable for human body temperature monitoring. IEEE Trans. Circuits Syst. II Express Briefs 2010, 57, 95-99. [CrossRef]

25. Wickramasinghe, A.; Ranasinghe, D.C. Ambulatory monitoring using passive computational RFID sensors. IEEE Sens. J. 2015, 15, 5859-5869. [CrossRef]

26. Manzari, S.; Catini, A.; Pomarico, G.; Di Natale, C.; Marrocco, G. Development of an UHF RFID chemical sensor array for battery-less ambient sensing. IEEE Sens. J. 2014, 14, 3616-3623. [CrossRef]

27. Caccami, M.; Mulla, M.; Occhiuzzi, C.; Di Natale, C.; Marrocco, G. Design and experimentation of a batteryless on-skin RFID graphene-oxide sensor for the monitoring and discrimination of breath anomalies. IEEE Sens. J. 2018, 18, 8893-8901. [CrossRef]

28. Boaventura, A.J.S.; Carvalho, N.B. A batteryless RFID remote control system. IEEE Trans. Microw. Theory Tech. 2013, 61, 2727-2736. [CrossRef]

29. Karmakar, N.C. Handbook of Smart Antennas for RFID Systems; John Wiley \& Sons: Hoboken, NJ, USA, 2011.

30. Thai, T.T.; Aubert, H.; Pons, P.; Tentzeris, M.M.; Plana, R. Design of a highly sensitive wireless passive RF strain transducer. In Proceedings of the 2011 IEEE MTT-S International Microwave Symposium, Baltimore, MD, USA, 5-10 June 2011; pp. 1-4.

31. Cook, B.S.; Shamim, A.; Tentzeris, M. Passive low-cost inkjet-printed smart skin sensor for structural health monitoring. IET Microw. Antennas Propag. 2012, 6, 1536-1541. [CrossRef]

32. Aubert, H.; Chebila, F.; Jatlaoui, M.; Thai, T.; Hallil, H.; Traille, A.; Bouaziz, S.; Rifai, A.; Pons, P.; Menini, P.; et al. Wireless sensing and identification of passive electromagnetic sensors based on millimetre-wave FMCW RADAR. In Proceedings of the 2012 IEEE International Conference on Rfid-Technologies and Applications (Rfid-Ta), Nice, France, 5-7 November 2012; pp. $398-403$.

33. Vyas, R.; Lakafosis, V.; Lee, H.; Shaker, G.; Yang, L.; Orecchini, G.; Traille, A.; Tentzeris, M.M.; Roselli, L. Inkjet printed, self powered, wireless sensors for environmental, gas, and authentication-based sensing. IEEE Sens. J. 2011, 11, 3139-3152. [CrossRef]

34. Potyrailo, R.A.; Nagraj, N.; Tang, Z.; Mondello, F.J.; Surman, C.; Morris, W. Battery-free radio frequency identification (RFID) sensors for food quality and safety. J. Agric. Food Chem. 2012, 60, 8535-8543. [CrossRef] [PubMed]

35. Zhang, C.; Huang, J.; Huang, Q. A passive wireless graphene oxide based humidity sensor and associated portable telemetry unit. In Proceedings of the 2013 Transducers \& Eurosensors XXVII: The 17th International Conference on Solid-State Sensors, Actuators and Microsystems (TRANSDUCERS \& EUROSENSORS XXVII), Barcelona, Spain, 16-20 June 2013; pp. $278-281$.

36. Honari, M.M.; Saghlatoon, H.; Mirzavand, R.; Mousavi, P. An RFID sensor for early expiry detection of packaged foods. In Proceedings of the 2018 18th International Symposium on Antenna Technology and Applied Electromagnetics (ANTEM), Waterloo, ON, Canada, 19-22 August 2018; pp. 1-2.

37. Saghlatoon, H.; Mirzavand, R.; Honari, M.M.; Mousavi, P. Sensor antenna transmitter system for material detection in wirelesssensor-node applications. IEEE Sens. J. 2018, 18, 8812-8819. [CrossRef]

38. Saghlatoon, H.; Mirzavand, R.; Mousavi, P. Fixed-frequency low-loss dielectric material sensing transmitter. IEEE Trans. Ind. Electron. 2020, 68, 3517-3526. [CrossRef]

39. Khalid, N.; Mirzavand, R.; Saghlatoon, H.; Honari, M.M.; Mousavi, P. A Three-Port Zero-Power RFID Sensor Architecture for IoT Applications. IEEE Access 2020, 8, 66888-66897. [CrossRef]

40. Khalid, N.; Mirzavand, R.; Saghlatoon, H.; Honari, M.M.; Mousavi, P. Three-Port Zero-Power RFID Flood Sensor for IoT Applications. In Proceedings of the 2020 IEEE Wireless Power Transfer Conference (WPTC), Seoul, Korea, 15-19 November 2020; pp. 61-64. [CrossRef]

41. Khalid, N.; Mirzavand, R.; Saghlatoon, H.; Honari, M.M.; Mousavi, P. A Three-Port Zero-Power RFID Wireless Sensor for IoT Applications. In Proceedings of the 2020 IEEE International Symposium on Antennas and Propagation and North American Radio Science Meeting (AP-S CNC/USNC-URSI), Montreal, QC, Canada, 5-10 July 2020; pp. 1-2. 
42. Fernández-Salmerón, J.; Rivadeneyra, A.; Martínez-Martí, F.; Capitán-Vallvey, L.F.; Palma, A.J.; Carvajal, M.A. Passive UHF RFID tag with multiple sensing capabilities. Sensors 2015, 15, 26769-26782. [CrossRef]

43. Kapucu, K.; Dehollain, C. A passive UHF RFID system with a low-power capacitive sensor interface. In Proceedings of the 2014 IEEE RFID Technology and Applications Conference (RFID-TA), Tampere, Finland, 8-9 September 2014; pp. 301-305.

44. Usami, R.; Komiyama, T.; Chonan, Y.; Yamaguchi, H.; Kotani, K. Photovoltaic-assisted self-Vth-cancellation CMOS rectifier for synergistic RF energy harvesting. IEICE Electron. Express 2020, 17, 1-6. [CrossRef]

45. Vyas, R.J.; Cook, B.B.; Kawahara, Y.; Tentzeris, M.M. E-WEHP: A batteryless embedded sensor-platform wirelessly powered from ambient digital-TV signals. IEEE Trans. Microw. Theory Tech. 2013, 61, 2491-2505. [CrossRef]

46. Sample, A.; Smith, J.R. Experimental results with two wireless power transfer systems. In Proceedings of the 2009 IEEE Radio and Wireless Symposium, San Diego, CA, USA, 18-22 January 2009; pp. 16-18.

47. Dolgov, A.; Zane, R.; Popovic, Z. Power management system for online low power RF energy harvesting optimization. IEEE Trans. Circuits Syst. I Regul. Pap. 2010, 57, 1802-1811. [CrossRef]

48. Farsense. Passive RFID Technology. Available online: http://www.farsens.com/en/2013/10/18/basic-guide-developing-rfidsensor-solutions / (accessed on 11 July 2021).

49. Sparkfun. UHF RFID Tag (Set of 5). Available online: https://www.sparkfun.com/products/14147 (accessed on 11 July 2021 ).

50. Weeglarski, M.; Jankowski-Mihułowicz, P.; Chamera, M.; Dziedzic, J.; Kwaśnicki, P. Designing Antennas for RFID Sensors in Monitoring Parameters of Photovoltaic Panels. Micromachines 2020, 11, 420. [CrossRef] [PubMed]

51. Chen, Z.N.; Qing, X. Antennas for RFID applications. In Final Program and Book of Abstracts—iWAT 2010: 2010 International Workshop on Antenna Technology: Small Antennas, Innovative Structures and Materials; IEEE: Lisbon, Portugal, 2010; pp. 13-16. [CrossRef]

52. Marrocco, G.; Fonte, A.; Bardati, F. Evolutionary design of miniaturized meander-line antennas for RFID applications. In Proceedings of the IEEE Antennas and Propagation Society International Symposium (IEEE Cat. No.02CH37313), San Antonio, TX, USA, 16-21 June 2002; Volume 2, pp. 362-365. [CrossRef]

53. Marrocco, G. Gain-optimized self-resonant meander line antennas for RFID applications. IEEE Antennas Wirel. Propag. Lett. 2003, 2, 302-305. [CrossRef]

54. Çiftçi, T.; Karaosmanoğlu, B.; Ergül. Low-cost inkjet antennas for RFID applications. IOP Conf. Ser. Mater. Sci. Eng. 2016, 120. [CrossRef]

55. Marrocco, G. The art of UHF RFID antenna design: Impedance-matching and size-reduction techniques. IEEE Antennas Propag. Mag. 2008, 50, 66-79. [CrossRef]

56. Švanda, M.; Polívka, M. Horizontal five-arm folded dipole over metal screening plane for UHF RFID of dielectric objects. Microw. Opt. Technol. Lett. 2010, 52, 2291-2294. [CrossRef]

57. Baumbauer, C.L.; Anderson, M.G.; Ting, J.; Sreekumar, A.; Rabaey, J.M.; Arias, A.C.; Thielens, A. Printed, flexible, compact UHF-RFID sensor tags enabled by hybrid electronics. Sci. Rep. 2020, 10, 1-12. [CrossRef] [PubMed]

58. Chen, H.D.; Tsao, Y.H. Low-profile meandered patch antennas for RFID tags mountable on metallic objects. IEEE Antennas Wirel. Propag. Lett. 2010, 9, 118-121. [CrossRef]

59. Genovesi, S.; Monorchio, A. Low-profile three-arm folded dipole antenna for UHF band RFID tags mountable on metallic objects. IEEE Antennas Wirel. Propag. Lett. 2010, 9, 1225-1228. [CrossRef]

60. Das, S.; Sawyer, D.J.; Diamanti, N.; Annan, A.P.; Iyer, A.K. A strongly miniaturized and inherently matched folded dipole antenna for narrowband applications. IEEE Trans. Antennas Propag. 2019, 68, 3377-3386. [CrossRef]

61. Das, S.; Saghlatoon, H.; Mousavi, P.; Iyer, A.K. A Highly Miniaturized and Inherently Conjugately Matched Folded Dipole-Based RFID Tag Antenna. IEEE Access 2019, 7, 101658-101664. [CrossRef]

62. Tedjini, S.; Vuong, T.P.; Beroulle, V. Antennas for RFID tags. ACM Int. Conf. Proc. Ser. 2005, 121, 19-22. [CrossRef]

63. Jheng, J.L.; Chen, H.D.; Kuo, S.H.; Yang, H.W. Circularly polarized RFID tag for metal surface mount. In Proceedings of the 2012 Asia-Pacific Microwave Conference Proceedings, APMC, Kaohsiung, Taiwan, 4-7 December 2012; pp. 1037-1039. [CrossRef]

64. Rahmani, H.; Babakhani, A. A dual-mode RF power harvesting system with an on-chip coil in 180-nm SOI CMOS for millimetersized biomedical implants. IEEE Trans. Microw. Theory Tech. 2018, 67, 414-428. [CrossRef]

65. Guler, U.; Jia, Y.; Ghovanloo, M. A reconfigurable passive RF-to-DC converter for wireless IoT applications. IEEE Trans. Circuits Syst. II Express Briefs 2019, 66, 1800-1804. [CrossRef]

66. Ma, C.; Zhang, C.; Wang, Z. A Low-Power AC/DC Rectifier for Passive UHF RFID T. In Proceedings of the 2007 International Symposium on Microwave, Antenna, Propagation and EMC Technologies for Wireless Communications, Hangzhou, China, 16-17 August 2007; pp. 309-314. [CrossRef]

67. Divakaran, S.K.; Krishna, D.D.; Nasimuddin. RF energy harvesting systems: An overview and design issues. Int. J. RF Microw. Comput. Aided Eng. 2019, 29, 1-15. [CrossRef]

68. Ghovanloo, M.; Atluri, S. An integrated full-wave CMOS rectifier with built-in back telemetry for RFID and implantable biomedical applications. IEEE Trans. Circuits Syst. I Regul. Pap. 2008, 55, 3328-3334. [CrossRef]

69. Mohd, Y.; Khaw, M.; Reaz, M. Radio frequency identification: Evolution of transponder circuit design. Microw. J. 2006, 49, 56.

70. Teh, Y.; Mohd-Yasin, F.; Choong, F.; Reaz, M.I. Development of CMOS UHF RFID modulator and demodulator using DTMOST techniques. In Proceedings of the 2009 IEEE 8th International Conference on ASIC, Changsha, China, 20-23 October 2009; pp. 561-564. [CrossRef] 
71. Bakhtiar, A.S.; Jalali, M.S.; Mirabbasi, S. A high-efficiency CMOS rectifier for low-power RFID tags. In Proceedings of the RFID 2010: International IEEE Conference on RFID, Orlando, FL, USA, 14-16 April 2010; pp. 83-88. [CrossRef]

72. Mandal, S.; Sarpeshkar, R. Low-power CMOS rectifier design for RFID applications. IEEE Trans. Circuits Syst. I Regul. Pap. 2007, 54, 1177-1188. [CrossRef]

73. Ashry, A.; Sharaf, K.; Ibrahim, M. A simple and accurate model for RFID rectifier. IEEE Syst. J. 2008, 2, 520-524. [CrossRef]

74. Yao, Y.; Wu, J.; Shi, Y.; Dai, F.F. A fully integrated 900-MHz passive RFID transponder front end with novel zero-threshold RF-DC rectifier. IEEE Trans. Ind. Electron. 2009, 56, 2317-2325. [CrossRef]

75. Wong, S.Y.; Chen, C. Power efficient multi-stage CMOS rectifier design for UHF RFID tags. Integr. VLSI J. 2011, 44, $242-255$. [CrossRef]

76. Theilmann, P.T.; Presti, C.D.; Kelly, D.; Asbeck, P.M. Near zero turn-on voltage high-efficiency UHF RFID rectifier in silicon-onsapphire CMOS. In Proceedings of the Digest of Papers-IEEE Radio Frequency Integrated Circuits Symposium, Anaheim, CA, USA, 23-25 May 2010; pp. 105-108.

77. Liu, H.; Vaddi, R.; Datta, S.; Narayanan, V. Tunnel FET-based ultra-low power, high-sensitivity UHF RFID rectifier. In Proceedings of the International Symposium on Low Power Electronics and Design (ISLPED), Beijing, China, 4-6 September 2013; pp. 157-162.

78. Teh, Y.K.; Lam, W.K.; Khaw, M.K.; Mohd-Yasin, F.; Reaz, M.I.; Sulaiman, M.S. The design of batteryless, TIRIS/spl reg/-compliant RFID transponder IC employing TSMC 0.18/spl mu/m process. In Proceedings of the 2004 IEEE International Conference on Semiconductor Electronics, Kuala Lumpur, Malaysia, 7-9 December 2004; p. 5. [CrossRef]

79. Grasso, L.; Sorbello, G.; Ragonese, E.; Palmisano, G. Codesign of differential-drive CMOS rectifier and inductively coupled antenna for RF harvesting. IEEE Trans. Microw. Theory Tech. 2020, 68, 364-375. [CrossRef]

80. Mui, K.M.; Khaw, M.K.; Mohd-Yasin, F. Power Management IC for a Dual-Input-Triple-Output Energy Harvester. Micromachines 2020, 11, 937. [CrossRef] [PubMed]

81. Lu, X.; Wang, P.; Niyato, D.; Kim, D.I.; Han, Z. Wireless networks with rf energy harvesting: A contemporary survey. IEEE Commun. Surv. Tutor. 2015, 17, 757-789. [CrossRef]

82. Guler, U.; Ghovanloo, M. Power Management in Wireless Power-Sipping Devices: A Survey. IEEE Circuits Syst. Mag. 2017, 17, 64-82. [CrossRef]

83. Teh, Y.; Mok, P.K.T. Design of Transformer-Based Boost Converter for High Internal Resistance Energy Harvesting Sources With $21 \mathrm{mV}$ Self-Startup Voltage and 74\% Power Efficiency. IEEE J. Solid-State Circuits 2014, 49, 2694-2704. [CrossRef]

84. Teh, Y.; Mohd-Yasin, F.; Choong, F.; Reaz, M.I.; Kordesch, A.V. Design and Analysis of UHF Micropower CMOS DTMOST Rectifiers. IEEE Trans. Circuits Syst. II Express Briefs 2009, 56, 122-126. [CrossRef]

85. Le, T.; Lakafosis, V.; Lin, Z.; Wong, C.P.; Tentzeris, M.M. Inkjet-printed graphene-based wireless gas sensor modules. In Proceedings of the Electronic Components and Technology Conference, San Diego, CA, USA, 29 May-1 June 2012; pp. 1003-1008. [CrossRef]

86. Le, T.; Lakafosis, V.; Kim, S.; Cook, B.; Tentzeris, M.M.; Lin, Z.; Wong, C.P. A novel graphene-based inkjet-printed WISP-enabled wireless gas sensor. In Proceedings of the European Microwave Week 2012: "Space for Microwaves", EuMW 2012, Conference Proceedings-42nd European Microwave Conference, EuMC 2012, Amsterdam, The Netherlands, 29 October-1 November 2012; pp. 412-415. [CrossRef]

87. Chen, Y.; Kao, H. Humidity sensors made on polyvinyl-alcohol film coated SAW devices. Electron. Lett. 2006, 42, 948-949. [CrossRef]

88. Oprea, A.; Barsan, N.; Weimar, U.; Bauersfeld, M.L.; Ebling, D.; Wollenstein, J. Capacitive Humidity Sensors on Flexible RFID Labels. In Proceedings of the TRANSDUCERS 2007-2007 International Solid-State Sensors, Actuators and Microsystems Conference, Lyon, France, 10-14 June 2007; pp. 2039-2042.

89. Mirzavand, R.; Honari, M.M.; Mousavi, P. High-resolution dielectric sensor based on injection-locked oscillators. IEEE Sens. J. 2017, 18, 141-148. [CrossRef]

90. Mirzavand, R.; Mousavi, P. A zero-power sensor using multi-port direct-conversion sensing. IEEE Sens. J. 2018, 18, 9243-9250. [CrossRef]

91. Ertuğ, B. The Fabrication of Porous Barium Titanate Ceramics via Pore-Forming Agents (PFAs) for Thermistor and Sensor Applications. Powder Metall. 2012, 4, 73-98.

92. Oprea, A.; Bârsan, N.; Weimar, U.; Bauersfeld, M.L.; Ebling, D.; Wöllenstein, J. Capacitive humidity sensors on flexible RFID labels. Sens. Actuators B Chem. 2008, 132, 404-410. [CrossRef]

93. Courbat, J.; Kim, Y.; Briand, D.; De Rooij, N. Inkjet printing on paper for the realization of humidity and temperature sensors. In Proceedings of the 2011 16th International Solid-State Sensors, Actuators and Microsystems Conference, Beijing, China, 5-9 June 2011; pp. 1356-1359.

94. Zhang, C.; Guo, L.; Wang, L.F.; Huang, J.Q.; Huang, Q.A. Passive wireless integrated humidity sensor based on dual-layer spiral inductors. Electron. Lett. 2014, 50, 1287-1289. [CrossRef]

95. Amin, E.M.; Bhuiyan, M.S.; Karmakar, N.C.; Winther-Jensen, B. Development of a low cost printable chipless RFID humidity sensor. IEEE Sens. J. 2013, 14, 140-149. [CrossRef]

96. Hester, J.; Tentzeris, M. Inkjet-printed Van-Atta reflectarray sensors: A new paradigm for long-range chipless low cost ubiquitous Smart Skin sensors of the Internet of Things. In Proceedings of the 2016 IEEE MTT-S International Microwave Symposium (IMS), San Francisco, CA, USA, 22-27 May 2016; pp. 1-4. 
97. Yang, H.; Ye, Q.; Zeng, R.; Zhang, J.; Yue, L.; Xu, M.; Qiu, Z.J.; Wu, D. Stable and fast-response capacitive humidity sensors based on a ZnO nanopowder/PVP-RGO multilayer. Sensors 2017, 17, 2415. [CrossRef]

98. Mirzavand, R.; Honari, M.M.; Laribi, B.; Khorshidi, B.; Sadrzadeh, M.; Mousavi, P. An unpowered sensor node for real-time water quality assessment (humic acid detection). Electronics 2018, 7, 231. [CrossRef]

99. Jiang, W.; Hong, T.; Gong, S. Research on the scattering characteristics and the RCS reduction of circularly polarized microstrip antenna. Int. J. Antennas Propag. 2013, 2013, 735847. [CrossRef]

100. Shrestha, S.; Balachandran, M.D.; Agarwal, M.; Zou, L.H.; Varahramyan, K. A method to measure radar cross section parameters of antennas. IEEE Trans. Antennas Propag. 2008, 56, 3494-3500. [CrossRef]

101. Knott, E.F.; Schaeffer, J.F.; Tulley, M.T. Radar Cross Section; SciTech Publishing: Edison, NJ, USA 2004.

102. McEntee, J. A Technique for Measuring the Scattering aPerture and Absorption Aperture of an Antenna; Antenna Laboratory, Ohio State University: Columbus, OH, USA, 1957.

103. Saghlatoon, H.; Honari, M.M.; Mirzavand, R.; Mousavi, P. Substrate integrated waveguide groove sensor antenna for permittivity measurements. In Proceedings of the 12th European Conference on Antennas and Propagation (EuCAP 2018), London, UK, 9-13 April 2018; pp. 1-3. [CrossRef]

104. Honari, M.M.; Mirzavand, R.; Saghlatoon, H.; Mousavi, P. A two-port microstrip sensor antenna for permittivity and loss tangent measurements. In Proceedings of the 2019 13th European Conference on Antennas and Propagation (EuCAP), Krakow, Poland, 31 March-5 April 2019; pp. 1-4.

105. Saghlatoon, H.; Mirzavand, R.; Honari, M.M.; Mousavi, P. Sensor antenna for dielectric constant measurement of materials in contact with the structure. In Proceedings of the 2019 13th European Conference on Antennas and Propagation (EuCAP), Krakow, Poland, 31 March-5 April 2019; pp. 1-3.

106. Behdani, M.; Kalateh, M.M.H.; Saghlatoon, H.; Melzer, J.; Mirzavand, R. High-Resolution Dielectric Constant Measurement Using a Sensor Antenna With an Allocated Link for Data Transmission. IEEE Sens. J. 2020, 20, 14827-14835. [CrossRef]

107. Yi, X.; Cho, C.; Wang, Y.; Cook, B.S.; Cooper, J.; Vyas, R.; Tentzeris, M.M.; Leon, R.T. Passive frequency doubling antenna sensor for wireless strain sensing. In Proceedings of the Smart Materials, Adaptive Structures and Intelligent Systems. American Society of Mechanical Engineers, Stone Mountain, GA, USA, 19-21 September 2012; Volume 45097, pp. 625-632.

108. Cho, C.; Yi, X.; Li, D.; Wang, Y.; Tentzeris, M.M. Passive wireless frequency doubling antenna sensor for strain and crack sensing. IEEE Sens. J. 2016, 16, 5725-5733. [CrossRef]

109. Song, G.; Zhang, B.; Lyu, Y.; Sun, T.; Wang, X.; He, C. Application of frequency doubling in micro-strip patch antenna for wireless strain detection. Sens. Actuators A Phys. 2020, 321, 112403. [CrossRef]

110. Mirzavand, R.; Honari, M.M.; Mousavi, P. N-ZERO direct conversion wireless sensor based on six-port structures. In Proceedings of the 2017 IEEE MTT-S International Microwave Symposium (IMS), Honololu, HI, USA, 4-9 June 2017; pp. $1225-1227$.

111. Mirzavand, R.; Honari, M.M.; Mousavi, P. Direct-conversion sensor for wireless sensing networks. IEEE Trans. Ind. Electron. 2017, 64, 9675-9682. [CrossRef]

112. Huang, X.; Leng, T.; Georgiou, T.; Abraham, J.; Nair, R.R.; Novoselov, K.S.; Hu, Z. Graphene oxide dielectric permittivity at GHz and its applications for wireless humidity sensing. Sci. Rep. 2018, 8, 1-7. [CrossRef] [PubMed]

113. Khalid, N.; Mirzavand, R.; Saghlatoon, H.; Honari Mohammad Mahdi, A.K.I.; Mousavi, P. A Battery-Less RFID Sensor Architecture with Distance Ambiguity Resolution for Smart Home IoT Applications. IEEE Internet Things J. 2021. [CrossRef]

114. Danneels, H.; Coddens, K.; Gielen, G. A fully-digital, 0.3 V, $270 \mathrm{nW}$ capacitive sensor interface without external references. In Proceedings of the 2011 Proceedings of the ESSCIRC (ESSCIRC), Helsinki, Finland, 12-16 September 2011; pp. $287-290$.

115. Mehmood, A.; He, H.; Chen, X.; Merilampi, S.; Sydänheimo, L.; Ukkonen, L.; Virkki, J. Body Movement-Based Controlling Through Passive RFID Integrated Into Clothing. IEEE J. Radio Freq. Identif. 2020, 4, 414-419. [CrossRef]

116. AMS. SL900A EPC Class 3 Sensory Tag Chip-For Automatic Data Logging Datasheet Addendum. Datasheet, AMS. October 2018. Available online: http:/ / ams.com (accessed on 10 July 2021). 